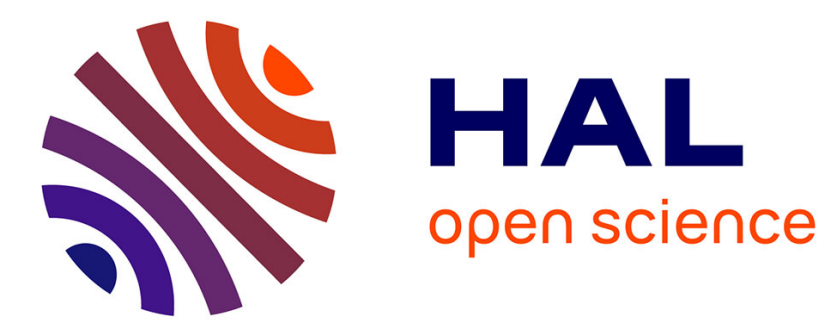

\title{
The photochemical fractionation of oxygen isotopologues in Titan's atmosphere
}

\author{
J.C. Loison, M. Dobrijevic, Kevin Hickson, A.N. Heays
}

\section{To cite this version:}

J.C. Loison, M. Dobrijevic, Kevin Hickson, A.N. Heays. The photochemical fractionation of oxygen isotopologues in Titan's atmosphere. Icarus, 2017, 291, pp.17-30. 10.1016/j.icarus.2017.02.032 . hal03107505

\section{HAL Id: hal-03107505 \\ https://hal.science/hal-03107505}

Submitted on 12 Jan 2021

HAL is a multi-disciplinary open access archive for the deposit and dissemination of scientific research documents, whether they are published or not. The documents may come from teaching and research institutions in France or abroad, or from public or private research centers.
L'archive ouverte pluridisciplinaire HAL, est destinée au dépôt et à la diffusion de documents scientifiques de niveau recherche, publiés ou non, émanant des établissements d'enseignement et de recherche français ou étrangers, des laboratoires publics ou privés. 


\title{
The photochemical fractionation of oxygen isotopologues in Titan's atmosphere
}

\author{
J.C. Loison ${ }^{b, c}$ M. Dobrijevic ${ }^{a}$ K.M. Hickson ${ }^{b, c}$ A. N. Heays ${ }^{d}$
}

a Laboratoire d'astrophysique de Bordeaux, Univ. Bordeaux, CNRS, B18N, alle Geoffroy Saint-Hilaire, 33615 Pessac, France

b Université de Bordeaux, Institut des Sciences Moléculaires, UMR 5255, F-33400 Talence, France

${ }^{\mathrm{c}} \mathrm{CNRS}$, Institut des Sciences Moléculaires, UMR 5255, F-33400 Talence, France

${ }^{\mathrm{d}}$ Leiden Observatory, Leiden University, PO Box 9513, 2300 RA Leiden, The Netherlands

Number of pages: 28

Number of tables: 2

Number of figures: 9 


\section{Proposed Running Head:}

Oxygen isotopologues in Titan's atmosphere

Please send Editorial Correspondence to:

Michel Dobrijevic

Laboratoire d'Astrophysique de Bordeaux

2 rue de l'observatoire, Floirac, F-33271, France.

Email: Michel.Dobrijevic@obs.u-bordeaux1.fr

Phone: +33-5-5777-6124 


\begin{abstract}
The origin of $\mathrm{CO}$ and the external source of $\mathrm{H}_{2} \mathrm{O}$ in the atmosphere of Titan is still a matter of debate. We investigated the chemical fractionation of oxygen isotopologues in order to give new constraints on the origin of oxygen species. We created a new chemical scheme and we developed a 1-D time-dependent photochemical model to compute the mole fraction profiles of various oxygen isotopologues. We show that the photochemical fractionation of oxygen isotopologues is quite low. Observations of $\mathrm{C}^{18} \mathrm{O}$ and $\mathrm{CO}^{18} \mathrm{O}$ are compatible with both an external origin or an internal origin of $\mathrm{CO}$ considering that the various sources of oxygen have a cometary ${ }^{16} \mathrm{O} /{ }^{18} \mathrm{O}$ ratio $\left({ }^{16} \mathrm{O} /{ }^{18} \mathrm{O} \approx 500\right)$. Improvement of the measurements of the ${ }^{16} \mathrm{O} /{ }^{18} \mathrm{O}$ ratio in both Enceladus' plumes and atmospheric $\mathrm{CO}_{2}$ could give a valuable constraint on the origin of oxygen in Titan's atmosphere.
\end{abstract}

Keywords: Titan ; Photochemistry ; Atmospheres ; Ionospheres 


\section{Introduction}

The atmosphere of Titan hosts a complex photochemistry producing hydrocarbons, nitriles, imines and oxygen compounds. Carbon monoxide is one of the most abundant molecules. It has been observed in many studies (see Serigano et al. (2016) for a recent review). However, its origin is still a matter of debate (Hörst et al., 2008; Bézard et al., 2012; Dobrijevic et al., 2014). Different scenarios have been proposed to explain its abundance but there are no definitive arguments to discriminate between an external origin of oxygen (micrometeorites, Enceladus' plumes) and an internal origin (outgassing of primordial CO from the surface). These two possible origins are supported by observations: the CAPS/Cassini instrument detected oxygen ions precipitating into Titan's atmosphere (Hartle et al., 2006) and the presence of ${ }^{36} \mathrm{Ar}$ detected by the GCMS/Huygens instrument (Niemann et al., 2010) shows that trapping of highly volatile gases, including possibly $\mathrm{N}_{2}$ and $\mathrm{CO}$, was possible during Titan's formation. In addition, the relative abundance of carbon dioxide, which has also been detected in the atmosphere, is not well understood (Hörst et al., 2008; Krasnopolsky, 2009; Moreno et al., 2012; Dobrijevic et al., 2014; Lara et al., 2014).

In principle, the study of isotopic ratios can give valuable constraints on the formation and evolution of planetary atmospheres. In particular, it could help to discriminate between different physical and chemical processes that have been or are presently preponderant. In this context, the study of oxygen isotopologues seems to be a promising step toward a better understanding of the origin and evolution of Titan's atmospheric composition. Several observations give some constraints on the ${ }^{16} \mathrm{O} /{ }^{18} \mathrm{O}$ ratio in Titan's atmosphere. The first estimation of ${ }^{16} \mathrm{O} /{ }^{18} \mathrm{O}$ ratio in the atmosphere of Titan was reported by Owen et al. (1999) using the James Clerk Maxwell Telescope with a preliminary value of 250 in $\mathrm{CO}$ (without error bars). From observations of submillimeter-wave rotational transitions of $\mathrm{CO}$ using the Submillimeter Array (SMA), Gurwell (2008) obtained a value of the ${ }^{16} \mathrm{O} /{ }^{18} \mathrm{O}$ ratio of $400 \pm 41$ (unpublished result, value reported in Courtin et al. (2011). According to Serigano et al. (2016), Gurwell et al. (2011) obtained a value of $472 \pm 104$ with the same set of observations (unpublished result). Using high-resolution submillimetric observations performed with the SPIRE instrument on the Herschel satellite, Courtin et al. (2011) determined a ${ }^{16} \mathrm{O} /{ }^{18} \mathrm{O}$ ratio equal to $380 \pm 60$ in $\mathrm{CO}$. Recently, from ALMA observations of CO, Serigano et al. (2016) obtained a ${ }^{16} \mathrm{O} /{ }^{18} \mathrm{O}$ ratio equal to $486 \pm 22$ and a ${ }^{16} \mathrm{O} /{ }^{17} \mathrm{O}$ ratio equal to $2917 \pm 359$. These latter results are in agreement with the terrestrial value of the ${ }^{16} \mathrm{O} /{ }^{18} \mathrm{O}$ ratio, which is 498.8 and the terrestrial value of ${ }^{16} \mathrm{O} /{ }^{17} \mathrm{O}$ ratio, which is 2680.0 (Lodders, 2003). Using the Cassini Composite Infrared Spectrometer (CIRS), Nixon et al. (2008) found a probable $3.5 \sigma$ detection of $\mathrm{CO}^{18} \mathrm{O}$ with the ratio $\mathrm{CO}_{2} / \mathrm{CO}^{18} \mathrm{O}=173 \pm 55$ leading to a ${ }^{16} \mathrm{O} /{ }^{18} \mathrm{O}$ ratio in $\mathrm{CO}_{2}$ of $346 \pm 110$. 
An update has been reported in Nixon et al. (2009), which revised the ratio upwards to $190 \pm 71$ (note that it encompasses the terrestrial value within error bars). If confirmed, these observations suggest that the ${ }^{16} \mathrm{O} /{ }^{18} \mathrm{O}$ ratio in $\mathrm{CO}_{2}$ could be lower than in $\mathrm{CO}$. This possible difference could be explained by chemical fractionation processes and/or could be the signature of several oxygen sources with different isotopic ratios.

In this paper, we present a new photochemical model to study the isotopic distribution between the various oxygen species to search for some additional constraints on the origin of oxygen in the atmosphere of Titan. In Section 2, we present the photochemical model and the chemical scheme with the different oxygen isotopologues and chemical and photolysis reactions that could lead to an isotopic fractionation. The main results are presented in Section 3. In Section 4, we discuss the sensitivity of the model to some parameters and the results of some previous models. The conclusions of this work are presented in Section 5.

\section{Model}

The model used in the present study is similar to the recent model of Dobrijevic et al. (2016), which couples ions and neutral species throughout the whole atmosphere (0-1500 km). Only additions and major modifications are outlined in the following.

\subsection{Chemical model}

The present model focuses on oxygen species and their isotopologues. Since we have to duplicate all reactions with isotopologues, computation time becomes huge when performing the uncertainty propagation model. So, we use a reduced chemical scheme for hydrocarbons and nitrogen species. It contains 71 species (47 neutrals and 24 ions) and 334 reactions (including photolysis processes). With this reduced scheme the densities of the major neutrals and ions are in a good agreement with our previous model and observations (see Dobrijevic et al. (2016) for comparison with various observations). Our reduced chemical scheme and the schematic diagrams highlighting the major production and loss pathways are given in appendix A.

The most noteworthy changes compared to Dobrijevic et al. (2016) are that we do not consider $\mathrm{C}_{3} \mathrm{H}_{x}$ compounds, as well as most of the $\mathrm{C}_{4} \mathrm{H}_{x}$ compounds and most of the complex nitriles. However, we always take into account the most important consumption reactions for all species present in our reduced 
model. When a product of a reaction is not in our model, we consider it as a sink. In some cases we have to consider relatively complex species, which play non-negligible roles in the abundance of lighter species (like $\mathrm{C}_{4} \mathrm{H}_{4}$ for $\mathrm{C}_{2} \mathrm{H}_{2}$ ). Some large cations (like $\mathrm{C}_{3} \mathrm{H}_{3}^{+}, \mathrm{C}_{3} \mathrm{H}_{5}^{+}$, etc.) are considered as reservoirs in our model (i.e. end product species of our chemical scheme that have no chemical loss process). We then consider Dissociative Recombination (DR) of this non specific reservoir cation, with a rate constant equal to $1.0 \times 10^{-6}(T / 300)^{-0.7}$ similar to the $\mathrm{DR}$ of $\mathrm{C}_{3} \mathrm{H}_{3}^{+}, \mathrm{C}_{3} \mathrm{H}_{5}^{+}$, etc, to reproduce the electron density as a function of altitude. We also introduced a $\mathrm{H}+$ neutral addition reaction to take into account the $\mathrm{H}+\mathrm{C}_{3} \mathrm{H}_{x}$ and $\mathrm{H}+\mathrm{C}_{4} \mathrm{H}_{x}(x=5-9)$ reactions which are not present in our reduced network and play a role at low altitude (with a mean altitude around $300 \mathrm{~km}$, see appendix C) as an important sink for $\mathrm{H}$ atoms. The rate constant for this addition reaction has been adjusted to reproduce the $\mathrm{H}$ atom abundance given by our more complete model (Loison et al., 2015). For oxygenated compounds we do not consider HNO and HNCO. HNO is not considered in this study compared to our previous study (Dobrijevic et al., 2014) because this molecule leads almost exclusively to NO in Titan's atmosphere. Then, we considered that the $\mathrm{N}\left({ }^{2} \mathrm{D}\right)+\mathrm{H}_{2} \mathrm{O}$ reaction gives, apart from $\mathrm{NH}+\mathrm{OH}$, directly $\mathrm{NO}+\mathrm{H}_{2}$ instead of $\mathrm{H}+\mathrm{HNO}$. We have considered the $\mathrm{NH}_{2}+\mathrm{NO}$ and $\mathrm{N}\left({ }^{2} \mathrm{D}\right)+\mathrm{H}_{2} \mathrm{CO}$ reactions as loss pathways for $\mathrm{NO}$ and $\mathrm{H}_{2} \mathrm{CO}$. These reactions produce $\mathrm{HNCO}$ which is not considered here. This does not affect notably the oxygenated chemical network as the main consumption of $\mathrm{HNCO}$ leads to $\mathrm{CO}$ through photodissociation, being a small contribution to the total CO production (only 0.1\% in the model Dobrijevic et al. (2014)). Anions are not taken into account in the present model since those with oxygen atoms are expected to have very low abundances particularly because oxygenated compounds have low Electron Affinities (Rienstra-Kiracofe et al., 2002). For all species in the present reduced model, the calculated abundances are very similar to the calculated ones with our more complete model (i.e. well within the error bars of the model results).

We have introduced several cations with the isotopologues of oxygen species. The effects of oxygenated cations are relatively minor, except for $\mathrm{H}_{2} \mathrm{CO}$ as the DR of $\mathrm{H}_{2} \mathrm{COH}^{+}$only partially gives back $\mathrm{H}_{2} \mathrm{CO}$ (Hamberg et al., 2007). The list of oxygen species included (neutrals, ions and their isotopologues) is given in Table 1.

Some chemical reactions may induce isotopic fractionation. Among them, the most promising reactions are $\mathrm{OH}+\mathrm{CO}, \mathrm{O}+\mathrm{CO}$ and $\mathrm{HCO}^{+}+\mathrm{CO}$. The reaction $\mathrm{OH}+\mathrm{CO}$ has been studied both theoretically (Chen and Marcus, 2005) and experimentally (Stevens et al., 1980; Rockmann et al., 1998; Feilberg et al., 2005) and shows some oxygen (and carbon) isotopic fractionation. Despite some disagreement between the various studies, all agree with the fact that the presence of ${ }^{18} \mathrm{O}$ slightly increases the rate constant with $k\left(\mathrm{OH}+\mathrm{C}^{18} \mathrm{O}\right)=k\left({ }^{18} \mathrm{OH}+\mathrm{CO}\right)=1 / 0.985 \times k(\mathrm{OH}+\mathrm{CO})$. The $\mathrm{O}+\mathrm{CO}$ reaction 
Table 1

List of the 28 oxygen species included in the model.

\begin{tabular}{|l|l|}
\hline Neutral species & Ions \\
\hline $\mathrm{O}\left({ }^{3} \mathrm{P}\right), \mathrm{O}\left({ }^{1} \mathrm{D}\right), \mathrm{OH}, \mathrm{H}_{2} \mathrm{O}, \mathrm{CO}, \mathrm{HCO}$, & $\mathrm{H}_{3} \mathrm{O}^{+}, \mathrm{HCO}^{+}, \mathrm{CH}_{2} \mathrm{OH}^{+}, \mathrm{NO}^{+}$ \\
$\mathrm{H}_{2} \mathrm{CO}, \mathrm{CH}_{3} \mathrm{O}, \mathrm{CO}_{2}, \mathrm{NO}$ & \\
${ }^{18} \mathrm{O}\left({ }^{3} \mathrm{P}\right),{ }^{18} \mathrm{O}\left({ }^{1} \mathrm{D}\right),{ }^{18} \mathrm{OH}, \mathrm{H}_{2}^{18} \mathrm{O}$, & $\mathrm{H}_{3}^{18} \mathrm{O}^{+}, \mathrm{HC}^{18} \mathrm{O}^{+}, \mathrm{CH}_{2}^{18} \mathrm{OH}^{+}, \mathrm{N}^{18} \mathrm{O}^{+}$ \\
$\mathrm{C}^{18} \mathrm{O}, \mathrm{HC}^{18} \mathrm{O}, \mathrm{H}_{2} \mathrm{C}^{18} \mathrm{O}, \mathrm{CH}_{3}{ }^{18} \mathrm{O}$, & \\
$\mathrm{CO}^{18} \mathrm{O}, \mathrm{N}^{18} \mathrm{O}$ & \\
\hline
\end{tabular}

leads to $\mathrm{CO}_{2}$ production with an activation barrier. This reaction plays a very minor role for $\mathrm{CO}_{2}$ production in Titan's atmosphere as the rate constant is small, but it might lead to a $\mathrm{C}^{18} \mathrm{O}$ enrichment. We use the experimental data from Jaffe and Klein (1966); Simonaitis and Heicklen (1972); Inn (1974) and the Mahata and Bhattacharya (2009) theoretical model values from their study of $\mathrm{CO}_{2}$ photodissociation. The last potentially important reaction for isotopic fractionation is the $\mathrm{CO}+\mathrm{HCO}^{+}$reaction. This reaction has been measured over the temperature range 80-500K (Smith and Adams 1980) and recently revisited (Mladenovic and Roueff 2009). The production of CO through photodissociation shows no fractionation in our model. Indeed, $\mathrm{CO}$ is produced from $\mathrm{H}_{2} \mathrm{CO}$ and $\mathrm{HCO}$ photodissociations, which occur mainly in the $\mathrm{UV}$ and in the visible range, where the solar flux is almost constant. Then, the Zero Point Energy (ZPE) effect on fractionation is negligible.

\subsection{High resolution photolysis rates}

The list of photolysis processes is given in appendix A. In our previous model, we used low resolution cross sections $(\Delta \lambda=1 \mathrm{~nm})$ for all the photolysis processes except for $\mathrm{N}_{2}$. In the present study, we introduce high resolution cross sections for several oxygen species, which are presented in appendix B. The photolysis rates of oxygen species and their isotopologues are presented in Figure 1. Except for $\mathrm{CO}_{2}$, the relative differences between the photolysis rates of the lighter species and their isotopologues are very low in our model. In particular, the relative difference between the photolysis rates of the $\mathrm{HCO}$ isotopologues is null because we consider that the cross section of $\mathrm{HC}^{18} \mathrm{O}$ is the same as the $\mathrm{HCO}$ one (see appendix B). Indeed, HCO is very efficiently photodissociated in the visible range, where the solar flux is constant. As a consequence, we consider that there is no ZPE effect for HCO. 

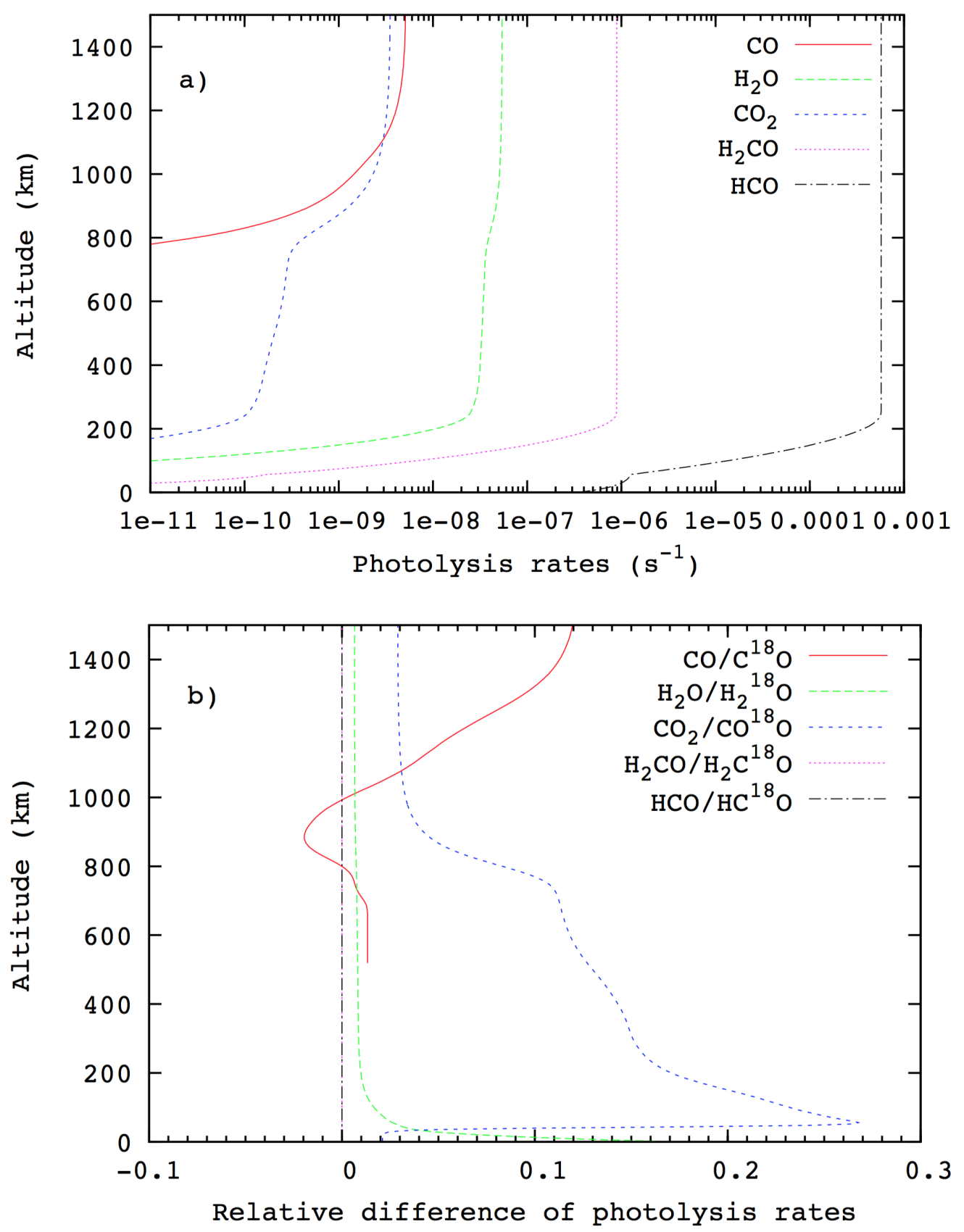

Fig. 1. a) Photolysis rates of the main neutral oxygen species in the model as a function of altitude. b) Relative difference of the photolysis rates for the two isotopologues of each compound.

\subsection{Boundary conditions for oxygen species}

Dobrijevic et al. (2014) discussed in detail the origin of oxygen species observed in Titan's atmosphere. They showed that several sources of oxygen species are possible and that different values of several parameters can give model 
results in agreement with observations. In the following, we do not consider this extensive set of parameters. Only two main scenarios are considered: (1) $\mathrm{CO}$ is continuously outgassed from the surface, (2) CO is only produced by the supply of external oxygen atoms from Enceladus' plumes and micrometeorites.

In the following, we present the isotopic ratio of oxygen species that are considered in the boundary conditions of our model. At the top of the atmosphere, oxygen could come from Enceladus' plumes or micrometeorites (in the form of $\mathrm{OH}$ and/or $\mathrm{H}_{2} \mathrm{O}$ ) (Hörst et al., 2008). Cassidy and Johnson (2010) simulated the evolution of the water molecules vented from Enceladus' south pole. They showed that this might be a significant source of oxygen atoms to Titan's upper atmosphere with a neutral $\mathrm{O}$ flux of $1-5 \times 10^{24} \mathrm{~s}^{-1}$ (see also Hartle et al. (2006) and Sittler et al. (2009) concerning the possible source of O in Titan's upper atmosphere). From INMS/Cassini, Waite et al. (2009) derived a measurement of the ${ }^{16} \mathrm{O} /{ }^{18} \mathrm{O}$ ratio in the Enceladus' plumes equal to $4766_{-76}^{+50}$. Bockelée-Morvan et al. (2012) measured the ${ }^{16} \mathrm{O} /{ }^{18} \mathrm{O}$ ratio in $\mathrm{H}_{2} \mathrm{O}$ in the Oort-cloud comet C/2009 P1 (Garradd) using the Herschel HIFI instrument. They found a value of $523 \pm 32$, which is in agreement with the results obtained by Biver et al. (2007) for 4 comets using the Odin satellite ( $508 \pm 33$, $530 \pm 60$ (twice) and $550 \pm 75$ ). Using the Ultraviolet-Visual Echelle Spectrograph (UVES) of the Very Large Telescope (VLT), Hutsemékers et al. (2008) found ${ }^{16} \mathrm{O} /{ }^{18} \mathrm{O}=425 \pm 55$ in $\mathrm{OH}$ in the Oort-Cloud comet $\mathrm{C} / 2002 \mathrm{~T} 7$ (LINEAR). Measurements obtained from the neutral mass spectrometer on the Giotto space probe gave the ${ }^{16} \mathrm{O} /{ }^{18} \mathrm{O}$ ratio in $\mathrm{H}_{3} \mathrm{O}^{+}$ion in comet $1 \mathrm{P} /$ Halley and allowed Eberhardt et al. (1995) to derive the ${ }^{16} \mathrm{O} /{ }^{18} \mathrm{O}$ ratio in $\mathrm{H}_{2} \mathrm{O}=$ $493 \pm 36$. Most of these data are in agreement with the terrestrial value of the ${ }^{16} \mathrm{O} /{ }^{18} \mathrm{O}$ ratio. As a consequence, the ${ }^{16} \mathrm{O} /{ }^{18} \mathrm{O}$ ratio in micrometeorites is likely to be terrestrial. At the lower boundary, $\mathrm{CO}$ might be outgassed from the surface. The latest measurements from ALMA observations favor a cometary ${ }^{16} \mathrm{O} /{ }^{18} \mathrm{O}$ ratio for $\mathrm{CO}$ (Serigano et al., 2016). However, when considering an internal origin for $\mathrm{CO}$, we also investigated various values of this ratio.

So, we have investigated various values as boundary conditions for the ${ }^{16} \mathrm{O} /{ }^{18} \mathrm{O}$ ratio in $\mathrm{O}\left({ }^{3} \mathrm{P}\right)$ (i.e. the Enceladus' plumes source), in $\mathrm{H}_{2} \mathrm{O}$ (micrometeorite source) and in CO (internal source).

\subsection{Vapor pressure}

We assume that the vapor pressure expressions of oxygen species that condense in the lower atmosphere (i.e. $\mathrm{H}_{2} \mathrm{O}, \mathrm{CO}_{2}$ and $\mathrm{H}_{2} \mathrm{CO}$ ) are identical to the ones of their respective isotopologues. Van Hook (1968) studied the vapor pressure isotope effects of $\mathrm{H}_{2} \mathrm{O}$ over liquid and ice. In particular, he found that the ratio between the vapor pressure of $\mathrm{H}_{2} \mathrm{O}$ and $\mathrm{H}_{2}^{18} \mathrm{O}$ is equal to 1.0165 at 233 
$\mathrm{K}$. Such a difference is very low compared to many other uncertainties in the model, especially in the chemistry. Moreover, since $\mathrm{H}_{2} \mathrm{O}$ is produced in the stratosphere and diffuses vertically down to the condensation level, this slight difference in the vapor pressure only leads to a slight difference in the level of condensation and has no noticeable incidence on the results of our model.

\section{$3 \quad$ Results}

\subsection{Internal source of $C O$}

In our internal model, we consider that $\mathrm{CO}$ is continuously outgassed from the surface, so the mole fraction of CO at the lower boundary (surface) is fixed to $5.1 \times 10^{-5}$ to be in agreement with observations (see Dobrijevic et al. (2014)) and we first consider that the ${ }^{16} \mathrm{O} /{ }^{18} \mathrm{O}$ ratio is the same as in comets. At the upper boundary (top of the atmosphere: $1500 \mathrm{~km})$, the flux of $\mathrm{O}\left({ }^{3} \mathrm{P}\right)$ from Enceladus' plumes is $1.6 \times 10^{6} \mathrm{~cm}^{-2} \mathrm{~s}^{-1}$ (Hörst et al., 2008; Dobrijevic et al., 2014) and the flux of water from micrometeorites is $1.0 \times 10^{6} \mathrm{~cm}^{-2} \mathrm{~s}^{-1}$. This value is twice the flux of water used in Dobrijevic et al. (2016). In the present model, the integrated photodissociation rate of $\mathrm{H}_{2} \mathrm{O}$ over the atmosphere is twice the value inferred in Dobrijevic et al. (2016) because of the use of the high resolution solar flux and absorption cross sections. As a consequence, the water flux required to compensate this photolytic loss is two times greater. For these two fluxes, we consider in our nominal model that the ${ }^{16} \mathrm{O} /{ }^{18} \mathrm{O}$ ratio is the same as in comets.

We first checked that our internal model is in agreement with our previous model and observations. Results are shown in Figure 2 and the mole fraction of water is in quite good agreement with the observation of Moreno et al. (2012). We note however that the use of high resolution solar flux and absorption cross sections have a noticeable effect on the water abundance profile in the lower atmosphere. For a detailed discussion on the disagreement between the observations of Moreno et al. (2012) and Cottini et al. (2012) for $\mathrm{H}_{2} \mathrm{O}$ and the disagreement between the model and observations for $\mathrm{CO}_{2}$, see Dobrijevic et al. (2014) and Lara et al. (2014). The main chemical production and loss processes for the various species are presented in appendix $\mathrm{C}$ together with all the integrated column rates. The ${ }^{16} \mathrm{O} /{ }^{18} \mathrm{O}$ ratio in the different oxygen species depends on the altitude according to the hydrostatic equilibrium and molecular diffusion. In particular, above the homopause (located around 900 $\mathrm{km}$ for $\mathrm{CH}_{4}$ in the present model), these physical processes lead to a depletion of ${ }^{18} \mathrm{O}$ compounds compared to ${ }^{16} \mathrm{O}$ compounds that exceeds the small contribution of photodissociations and/or chemical reactions in the fractionation of isotopologues. In the troposphere, some species condense (like $\mathrm{CO}_{2}$ 
and $\mathrm{H}_{2} \mathrm{O}$ ) and their isotopologue ratio then remains constant. In the middle atmosphere, around $600 \mathrm{~km}$, the calculated ${ }^{16} \mathrm{O} /{ }^{18} \mathrm{O}$ ratios in $\mathrm{H}_{2} \mathrm{O}, \mathrm{CO}$ and $\mathrm{CO}_{2}$ are 497, 500 and 484 respectively. So, there is a slight photochemical fractionation for $\mathrm{CO}_{2}$ since we should expect a ${ }^{16} \mathrm{O} /{ }^{18} \mathrm{O}$ ratio equal to 500 for this species too. This small isotopic $\mathrm{CO}_{2}$ fractionation comes mainly from the $\mathrm{OH}+\mathrm{CO}$ reaction. There is also a small contribution from $\mathrm{CO}_{2}$ photodissociation. The nominal value of $\mathrm{CO}_{2} / \mathrm{CO}^{18} \mathrm{O}$ ratio we obtained (242) is different from the nominal value inferred by Nixon et al. (2009) (190 \pm 71$)$. However, the uncertainty on this value is large and any conclusion may be premature. Since $\mathrm{CO}_{2}$ is produced mainly through the $\mathrm{OH}+\mathrm{CO}$ reaction, and since we do not find any isotope fractionation in $\mathrm{CO}$, a low value of the $\mathrm{CO}_{2} / \mathrm{CO}^{18} \mathrm{O}$ ratio (if confirmed) would suggest that the ${ }^{16} \mathrm{O} /{ }^{18} \mathrm{O}$ ratio in $\mathrm{OH}$ (and consequently in $\mathrm{H}_{2} \mathrm{O}$ ) is not cometary or that there is a photochemical fractionation that is not considered in our model (or also that there are some observational issues). In conclusion, additional observations of both $\mathrm{CO}_{2}$ and $\mathrm{CO}^{18} \mathrm{O}$ would be valuable to better constrain the model.

$\mathrm{CO}$ and $\mathrm{C}^{18} \mathrm{O}$ are the main reservoirs of oxygen isotopologues in Titan's atmosphere. Although the $\mathrm{CO}+\mathrm{HCO}^{+}$reaction is characterized by large fluxes, $\mathrm{HCO}^{+}$is involved in reactions leading ultimately back to $\mathrm{CO}$. So, the $\mathrm{CO}+$ $\mathrm{HCO}^{+}$reaction does not lead to any isotopic $\mathrm{C}^{18} \mathrm{O}$ fractionation, but instead it controls the $\mathrm{HCO}^{+} / \mathrm{HC}^{18} \mathrm{O}^{+}$ratio. Since there is no efficient fractionation in $\mathrm{CO}$ in our model, this indicates that the current observed value of ${ }^{16} \mathrm{O} /{ }^{18} \mathrm{O}$ in $\mathrm{CO}$ corresponds to the $\mathrm{CO} / \mathrm{C}^{18} \mathrm{O}$ ratio continuously outgassed by the surface. Fractionation could occur during outgassing but it might be quite low. Indeed, $\mathrm{C}^{18} \mathrm{O}$ could be slightly more abundant in clathrates than $\mathrm{C}^{16} \mathrm{O}$ but outgassing might slightly favor $\mathrm{C}^{16} \mathrm{O}$ (Hesse and Harrison, 1981; Clark and Fritz, 1997). These two processes induce a fractionation around 1\%. As a consequence, a cometary ${ }^{16} \mathrm{O} /{ }^{18} \mathrm{O}$ ratio is expected in primordial $\mathrm{CO}$, which is compatible with observations and our model.

The abundance profiles of the other neutral oxygen species included in our model are shown in Figure 3. The only other oxygenated molecule relatively abundant in the ionosphere is $\mathrm{H}_{2} \mathrm{CO}\left(\mathrm{H}_{2} \mathrm{CO}\right.$ is produced mainly through the $\mathrm{O}$ $+\mathrm{CH}_{3}$ reaction with a minor contribution of $\mathrm{OH}+\mathrm{CH}_{3}$, which are among the most important reactions involving oxygen species in Titan's atmosphere). All the oxygen species have abundances that strongly decrease in the stratosphere with decreasing altitude. The species which is the subject of the most important fractionation by photochemical processes in the ionosphere is NO. At the lower boundary of the ionosphere (around $800 \mathrm{~km}$ ), the ${ }^{16} \mathrm{O} /{ }^{18} \mathrm{O}$ ratio in $\mathrm{NO}$ is equal to 544 (see Table 2). The chemical production of $\mathrm{NO}\left(\mathrm{N}_{2} \mathrm{D}\right)+\mathrm{H}_{2} \mathrm{O}$ and $\mathrm{N}+\mathrm{OH})$ as well as its loss $\left(\mathrm{N}+\mathrm{NO}\right.$ and $\left.\mathrm{CH}_{2}+\mathrm{NO}\right)$ are thought to be the same for ${ }^{16} \mathrm{O}$ and ${ }^{18} \mathrm{O}$ compounds leading to no fractionation. Moreover, NO photodissociation is a very minor destruction process. At high altitude $\mathrm{N}^{18} \mathrm{O}$ is depleted as diffusion is controlled by the mass and this depletion propagates 

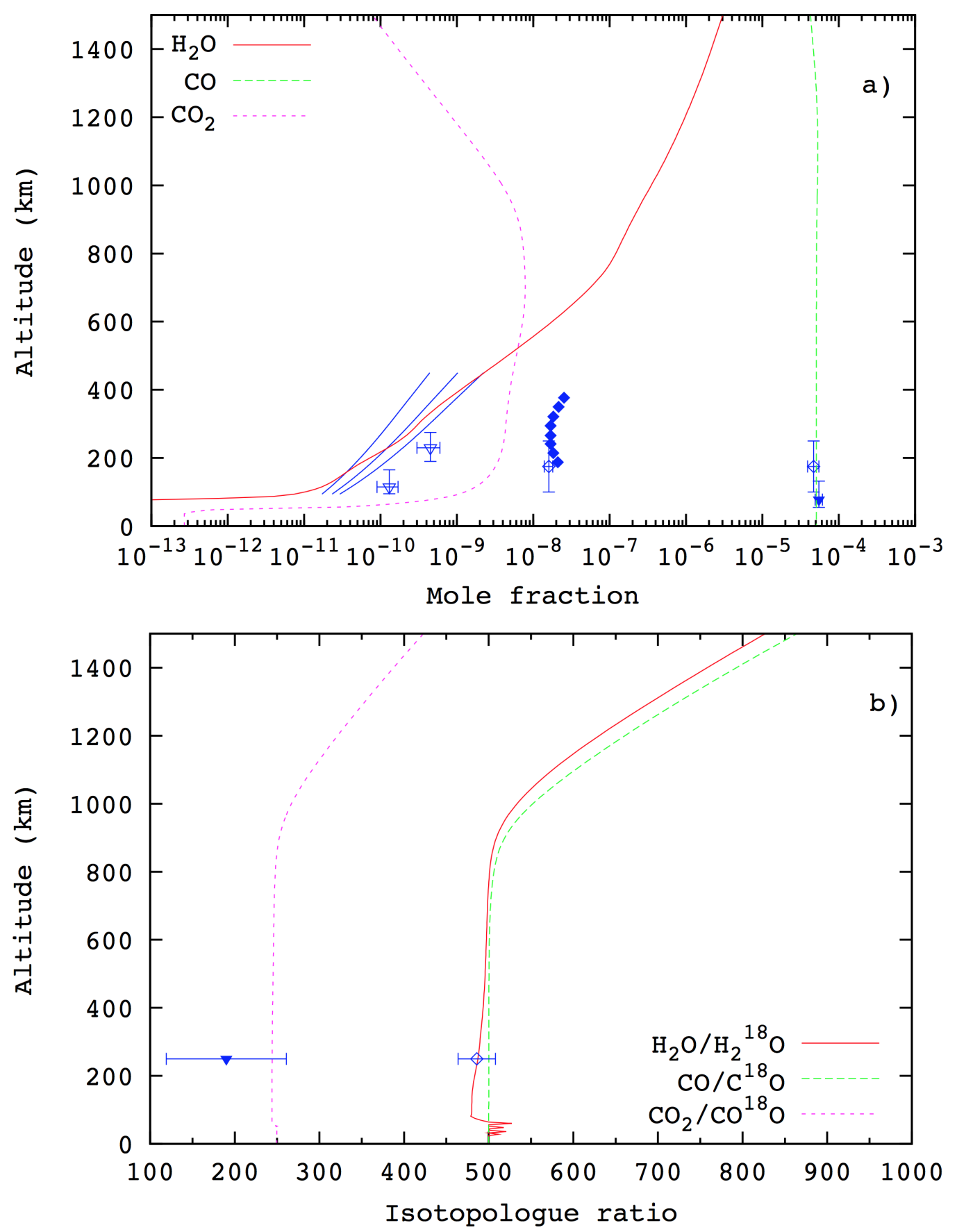

Fig. 2. a) Mole fraction profile of $\mathrm{H}_{2} \mathrm{O}$ (solid line), $\mathrm{CO}$ (long dashed line) and $\mathrm{CO}_{2}$ (short dashed line) as a function of altitude in the nominal model (internal $\mathrm{CO}, \mathrm{O}\left({ }^{3} \mathrm{P}\right)$ from Enceladus' plumes and $\mathrm{H}_{2} \mathrm{O}$ from micrometeorites). Observations (in blue) of Moreno et al. (2012) (solid lines for mean and 1-sigma uncertainty), Cottini et al. (2012) (triangles) for $\mathrm{H}_{2} \mathrm{O}$, observations of $\mathrm{CO}$ and $\mathrm{CO}_{2}$ from de Kok et al. (2007) (diamond) and CO observation of Teanby et al. (2010) (triangle) are shown for comparison. b) $\mathrm{H}_{2} \mathrm{O} / \mathrm{H}_{2}{ }^{18} \mathrm{O}, \mathrm{CO} / \mathrm{C}^{18} \mathrm{O}$ and $\mathrm{CO}_{2} / \mathrm{CO}^{18} \mathrm{O}$ as a function of altitude. Values inferred from observations of Serigano et al. (2016) and Nixon et al. (2009) are given for $\mathrm{CO}$ (diamond) and $\mathrm{CO}_{2}$ (triangle). Due to very low abundances, numerical fluctuations appear in the lower troposphere. 
in the stratosphere. The fractionation in $\mathrm{H}_{2} \mathrm{CO}$, is quite low since the ${ }^{16} \mathrm{O} /{ }^{18} \mathrm{O}$ ratio in $\mathrm{H}_{2} \mathrm{CO}$ is equal to 485 at $800 \mathrm{~km}$. The photodissociation of $\mathrm{H}_{2} \mathrm{CO}$ is slightly different from the one of $\mathrm{H}_{2} \mathrm{C}^{18} \mathrm{O}$ in our model, which induces some fractionation and finally leads to a small enrichment in $\mathrm{H}_{2} \mathrm{C}^{18} \mathrm{O}$. Below 500 $\mathrm{km}$, the main source of $\mathrm{H}_{2} \mathrm{CO}$ is the $\mathrm{O}\left({ }^{3} \mathrm{P}\right)+\mathrm{CH}_{3}$ reaction, $\mathrm{O}\left({ }^{3} \mathrm{P}\right)$ atoms coming at this altitude mainly from the photodissociation of $\mathrm{CO}_{2}$. Then, the change in the $\mathrm{H}_{2} \mathrm{CO} / \mathrm{H}_{2} \mathrm{C}^{18} \mathrm{O}$ profile (and in some other species) comes from fractionation of $\mathrm{CO}_{2}$ by photodissociation. This fractionation has no, or very little effect on $\mathrm{HCO}$ because at this altitude $\mathrm{HCO}$ is produced mostly by the $\mathrm{H}+\mathrm{CO}$ reaction rather than the photodissociation of $\mathrm{H}_{2} \mathrm{CO}$. For that reason, the $\mathrm{HCO} / \mathrm{HC}^{18} \mathrm{O}$ ratio is equal to $\mathrm{CO} / \mathrm{C}^{18} \mathrm{O}$. The depletion of ${ }^{18} \mathrm{O}$ species at $800 \mathrm{~km}$ and $500 \mathrm{~km}$ is due to the fact that $\mathrm{H}_{2}{ }^{18} \mathrm{O}$ and $\mathrm{CO}^{18} \mathrm{O}$ are less photodissociated than $\mathrm{H}_{2} \mathrm{O}$ and $\mathrm{CO}_{2}$ respectively (cross sections of these species are slightly displaced for the isotopologues), leading to depletion in ${ }^{18} \mathrm{O}\left({ }^{1} \mathrm{D}\right)$ and ${ }^{18} \mathrm{O}\left({ }^{3} \mathrm{P}\right)$ which are produced by the photodissociation of both $\mathrm{H}_{2} \mathrm{O}$ and $\mathrm{CO}_{2}$. The relative importance of these photolyses change as a function of altitude, then the ${ }^{16} \mathrm{O}\left({ }^{1} \mathrm{D}\right) /{ }^{18} \mathrm{O}\left({ }^{1} \mathrm{D}\right)$ and ${ }^{16} \mathrm{O}\left({ }^{3} \mathrm{P}\right) /{ }^{18} \mathrm{O}\left({ }^{3} \mathrm{P}\right)$ ratios have slightly different values at different altitudes.

Densities of oxygen ions are shown in Figure 4. The main oxygen ion in our model is $\mathrm{CH}_{2} \mathrm{OH}^{+}$, which is about 100 times lower than the most abundant ion in the ionosphere $\left(\mathrm{HCNH}^{+}\right) . \mathrm{CH}_{2} \mathrm{OH}^{+}$cannot be detected in INMS/Cassini data because of the presence of a contribution from $\mathrm{C}_{2} \mathrm{H}_{6}$ in the mass spectrum at the mass 31 amu. Like $\mathrm{NO}, \mathrm{NO}^{+}$is the species with the largest photochemical fractionation. This is due to the fact that $\mathrm{NO}^{+}$is formed through charge exchange between $\mathrm{CH}_{3}^{+}, \mathrm{CH}_{4}^{+}$and $\mathrm{NO}$ so that the fractionation of $\mathrm{NO}$ and $\mathrm{NO}^{+}$are similar.

The most important chemical pathways for ${ }^{16} \mathrm{O}$ and ${ }^{18} \mathrm{O}$ oxygenated compounds are presented in Figure 5. It highlights which compounds are subject to a photochemical fractionation. In order to confirm this scheme, we computed the isotopic ratios of all the oxygen compounds when changing the $\mathrm{CO} / \mathrm{C}^{18} \mathrm{O}$ ratio at the lower boundary of our model. The evolution of the isotopologue ratios for several compounds as a function of the primordial $\mathrm{CO} / \mathrm{C}^{18} \mathrm{O}$ ratio (from 300 to 700) at the lower boundary is shown in Figure 6. Results are given at $250 \mathrm{~km}$ of altitude, a region where sub-millimeter and infrared observations are available. The observational values (and their error bars) of Serigano et al. (2016) for $\mathrm{CO}$ and Nixon et al. (2008) for $\mathrm{CO}_{2}$ are also depicted. Given the observational error bars, our model is currently in agreement with data but future observations of $\mathrm{CO}^{18} \mathrm{O}$ would be interesting to take this comparison further. We see that the $\mathrm{HCO}^{+} / \mathrm{HC}^{18} \mathrm{O}^{+}$and $\mathrm{H}_{2} \mathrm{CO} / \mathrm{H}_{2} \mathrm{C}^{18} \mathrm{O}$ ratios are strongly affected by the $\mathrm{CO} / \mathrm{C}^{18} \mathrm{O}$ ratio (the $\mathrm{HCO}^{+} / \mathrm{HC}^{18} \mathrm{O}^{+}$ratio is almost equal to $\mathrm{CO}^{+} / \mathrm{C}^{18} \mathrm{O}^{+}$ratio). The $\mathrm{CO}_{2} / \mathrm{CO}^{18} \mathrm{O}$ ratio is noticeably affected. We also note that the evolution of the $\mathrm{H}_{2} \mathrm{CO} / \mathrm{H}_{2} \mathrm{C}^{18} \mathrm{O}$ ratio is fully correlated to the $\mathrm{CH}_{2} \mathrm{OH}^{+} / \mathrm{CH}_{2}{ }^{18} \mathrm{OH}^{+}$ratio, $\mathrm{NO} / \mathrm{N}^{18} \mathrm{O}$ is fully correlated to $\mathrm{NO}^{+} / \mathrm{N}^{18} \mathrm{O}^{+}$and 

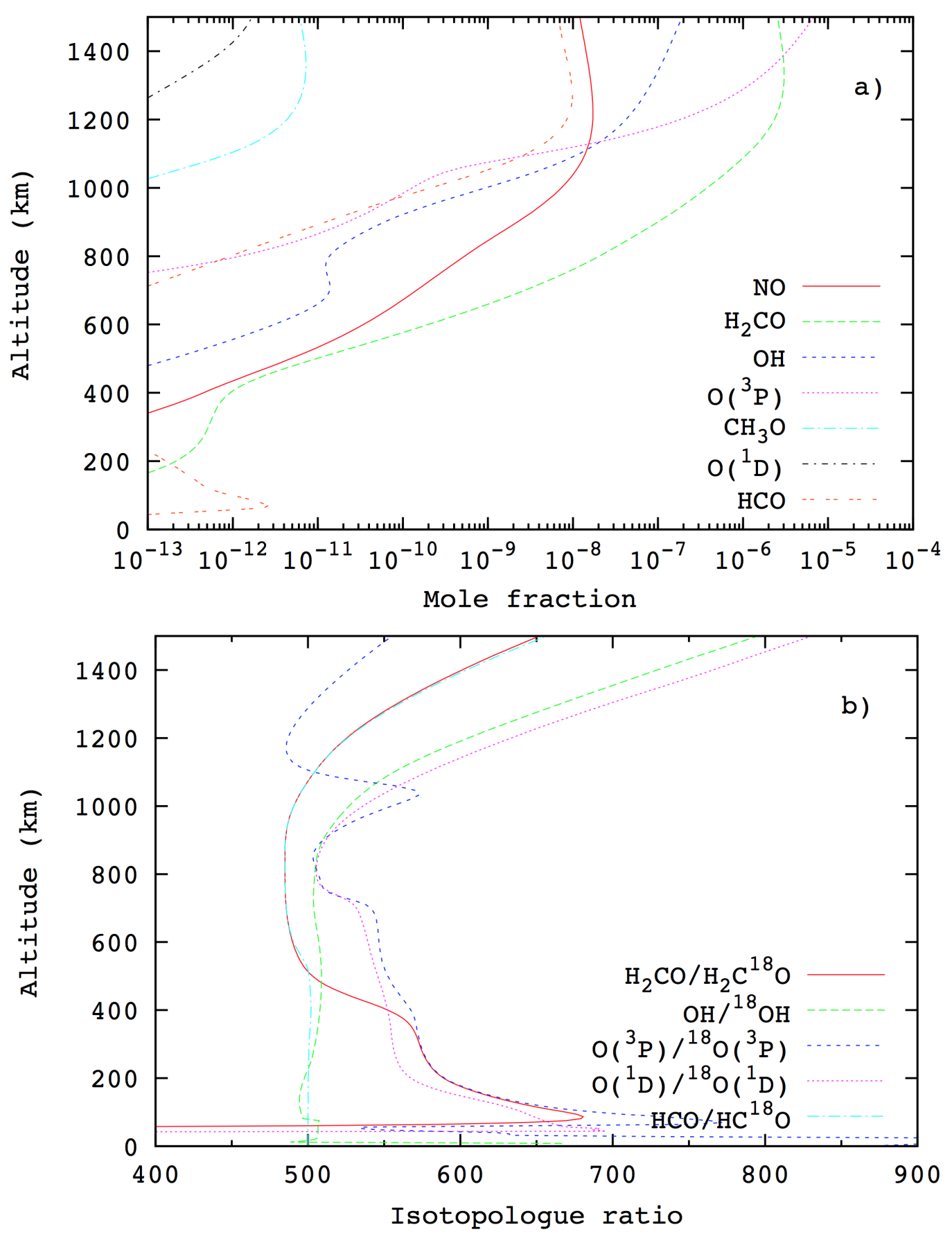

Fig. 3. a) Mole fraction profiles of neutral oxygen species as a function of altitude in the nominal model. b) isotopologue ratio of some neutral species as a function of altitude. Due to very low abundances, numerical fluctuations appear in the lower troposphere. 

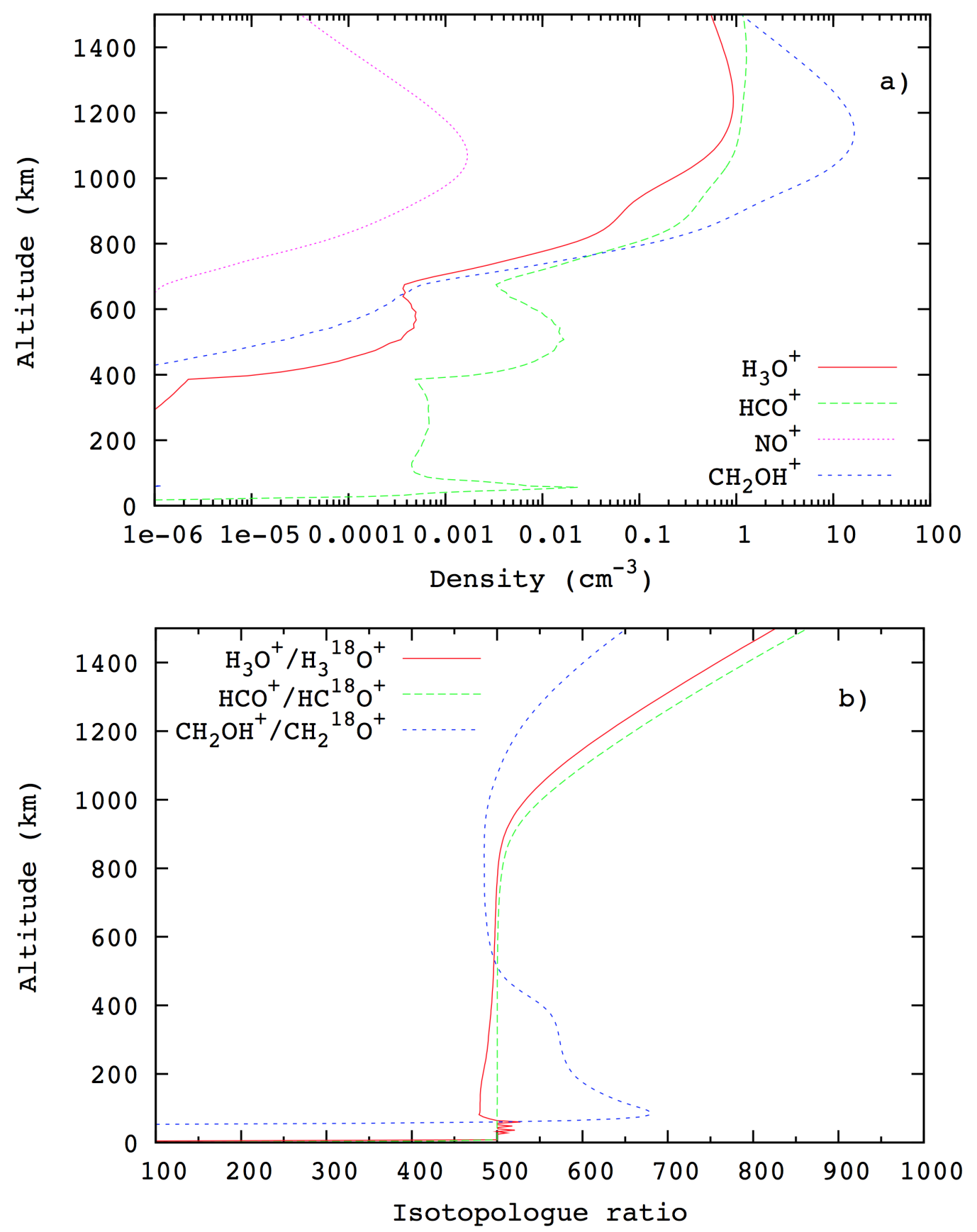

Fig. 4. a) density profiles of oxygen ions as a function of altitude in the nominal model. b) isotopologue ratio of some ions as a function of altitude. Due to very low abundances, numerical fluctuations appear in the lower troposphere.

$\mathrm{H}_{2} \mathrm{O} / \mathrm{H}_{2}{ }^{18} \mathrm{O}$ to $\mathrm{H}_{3} \mathrm{O}^{+} / \mathrm{H}_{3}{ }^{18} \mathrm{O}^{+}$. All these behaviours are in agreement with the simple chemical scheme shown in Figure 5.

In conclusion, considering that the external $\mathrm{O}\left({ }^{3} \mathrm{P}\right)$ and $\mathrm{H}_{2} \mathrm{O}$ fluxes, and the internal CO outgassed from the surface, all have a ${ }^{16} \mathrm{O} /{ }^{18} \mathrm{O}$ ratio equal to 500 , our model is consistent with current observations of the two $\mathrm{CO} / \mathrm{C}^{18} \mathrm{O}$ and 

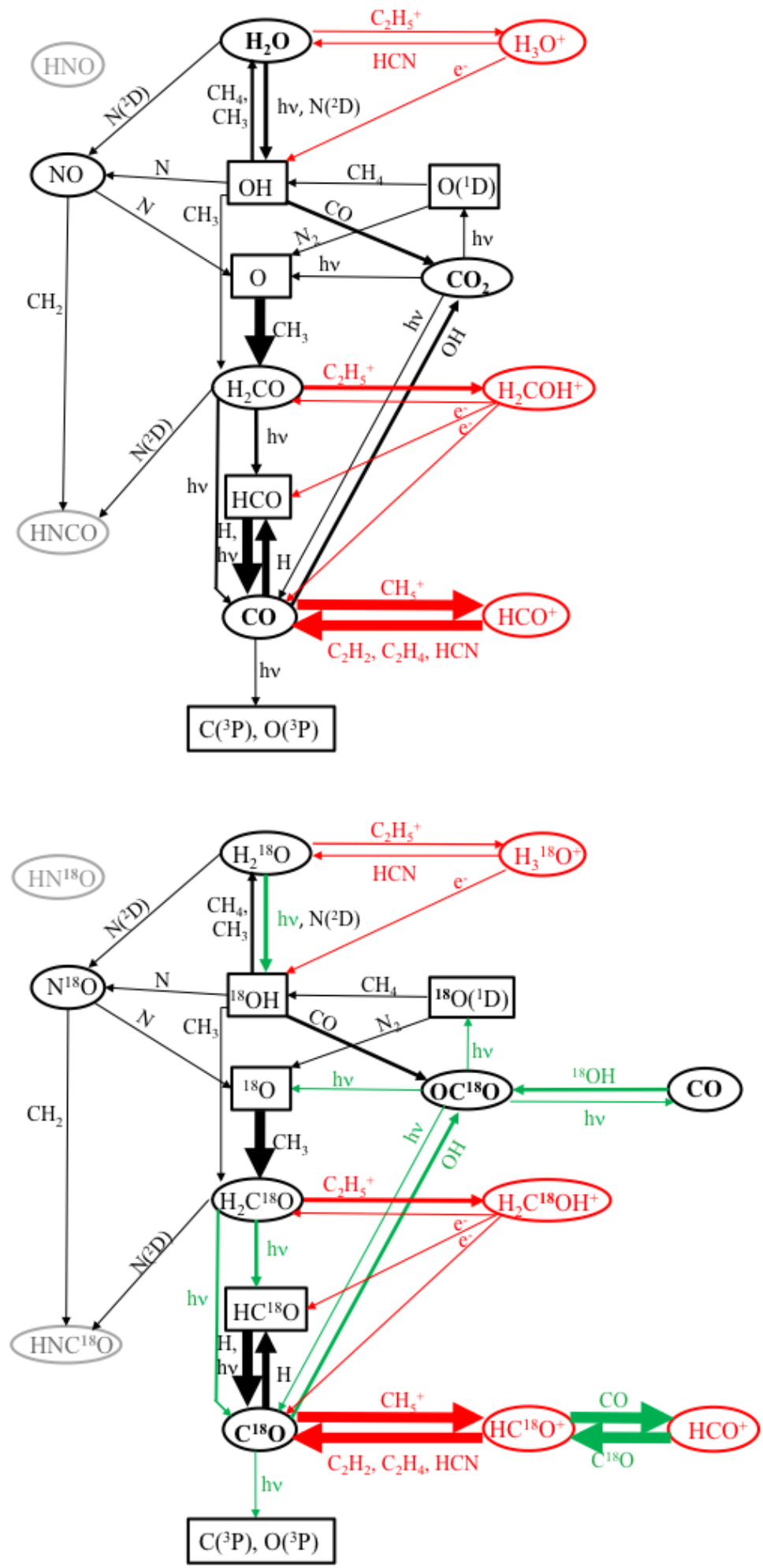

Fig. 5. Schematic diagram highlighting the important pathways for the chemistry of ${ }^{16} \mathrm{O}$ and ${ }^{18} \mathrm{O}$ containing compounds. The thickness of each arrow represents the integrated total production. The use of red as a color corresponds to ionic chemistry. Species in gray are not considered in this study. Compounds that have been detected are highlighted in bold. Processes in green correspond to reactions which may induce some fractionation. 


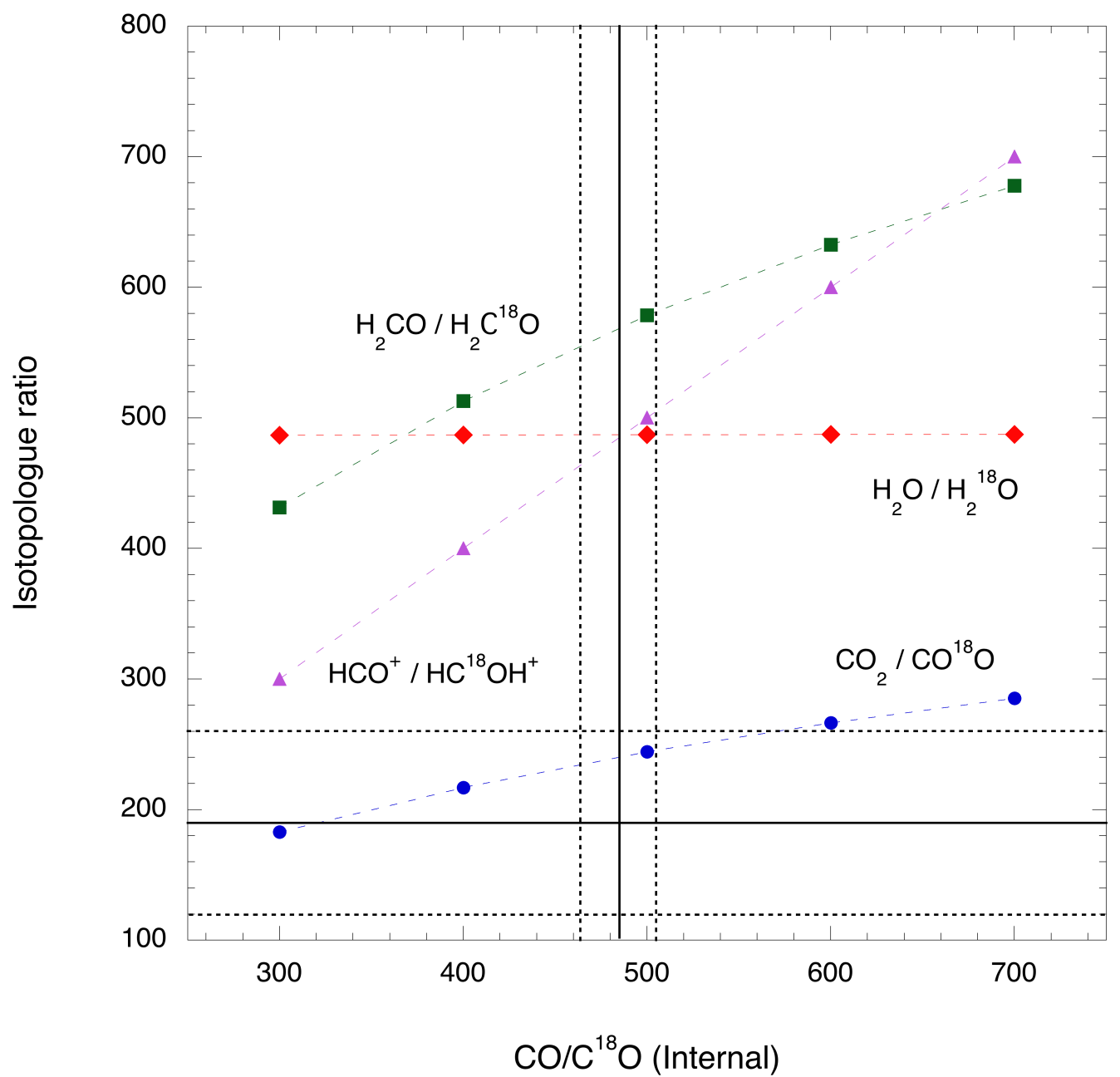

Fig. 6. The $\mathrm{CO}_{2} / \mathrm{CO}^{18} \mathrm{O}$ (blue disk), $\mathrm{H}_{2} \mathrm{CO} / \mathrm{H}_{2} \mathrm{C}^{18} \mathrm{O}$ (red diamond), $\mathrm{H}_{2} \mathrm{O} / \mathrm{H}_{2}{ }^{18} \mathrm{O}$ (green square) and $\mathrm{HCO}^{+} / \mathrm{HC}^{18} \mathrm{O}^{+}$(purple triangle) ratios at $250 \mathrm{~km}$ of altitude (region where observations are available) as a function of the $\mathrm{CO} / \mathrm{C}^{18} \mathrm{O}$ ratio fixed at the lower boundary. Note that the $\mathrm{CH}_{2} \mathrm{OH}^{+} / \mathrm{CH}_{2}{ }^{18} \mathrm{OH}^{+}$ratio has the same evolution as $\mathrm{H}_{2} \mathrm{CO} / \mathrm{H}_{2} \mathrm{C}^{18} \mathrm{O}$. Horizontal line: $\mathrm{CO}_{2} / \mathrm{CO}^{18} \mathrm{O}$ value from Nixon et al. (2009). Vertical line: $\mathrm{CO} / \mathrm{C}^{18} \mathrm{O}$ value from Serigano et al. (2016). Black dashed lines represent error bars of observations.

$\mathrm{CO}_{2} / \mathrm{CO}^{18} \mathrm{O}$ ratios.

\subsection{External source of $\mathrm{CO}$}

We have also investigated the production of oxygen compounds $\left(\mathrm{CO}, \mathrm{CO}_{2}, \ldots\right)$ through an external supply of oxygen via micrometeorites (in the form of $\mathrm{H}_{2} \mathrm{O}$ ) and Enceladus' plumes (in the form of $\mathrm{O}\left({ }^{3} \mathrm{P}\right)$ ). The integration time needed to obtain a $\mathrm{CO}$ mole fraction of about $4.5 \times 10^{-5}$ is equal to $10^{16} \mathrm{~s}$ $\left(317 \times 10^{6}\right.$ years $)$. At this time, the mole fractions of the major oxygen species 
are identical to the ones obtained with the internal scenario (see Dobrijevic et al. (2014) for details). This confirms that different scenarios give the same profiles of $\mathrm{CO}$ and $\mathrm{CO}_{2}$.

Although values derived from Waite et al. (2009) for the ${ }^{16} \mathrm{O} /{ }^{18} \mathrm{O}$ ratio in the Enceladus' plumes range from 400 to 526, we have investigated larger variations of this ratio. We first consider that the ${ }^{16} \mathrm{O} /{ }^{18} \mathrm{O}$ ratio in $\mathrm{H}_{2} \mathrm{O}$ from micrometeorites is constant and equal to 500 (see section 4.2 for a study of this parameter). Results are shown in Figure 7 . The most striking results are the following: (1) the evolution of the $\mathrm{CO} / \mathrm{C}^{18} \mathrm{O}$ and $\mathrm{H}_{2} \mathrm{CO} / \mathrm{H}_{2} \mathrm{C}^{18} \mathrm{O}$ ratios are strongly correlated with the external $\mathrm{O}\left({ }^{3} \mathrm{P}\right) /{ }^{18} \mathrm{O}\left({ }^{3} \mathrm{P}\right)$ flux from Enceladus, (2) as a consequence, the evolution of $\mathrm{CO}_{2} / \mathrm{CO}^{18} \mathrm{O}$ and the $\mathrm{HCO}^{+} / \mathrm{HC}^{18} \mathrm{O}^{+}$ratios are similar to the internal case since they are correlated to the $\mathrm{CO} / \mathrm{C}^{18} \mathrm{O}$ ratio.

In conclusion, considering that the external $\mathrm{H}_{2} \mathrm{O}$ and $\mathrm{O}\left({ }^{3} \mathrm{P}\right) /{ }^{18} \mathrm{O}\left({ }^{3} \mathrm{P}\right)$ fluxes both have a ${ }^{16} \mathrm{O} /{ }^{18} \mathrm{O}$ ratio equal to 500 , our model is consistent with current observations of both $\mathrm{CO} / \mathrm{C}^{18} \mathrm{O}$ and $\mathrm{CO}_{2} / \mathrm{CO}^{18} \mathrm{O}$ ratios. The $\mathrm{CO}_{2} / \mathrm{CO}^{18} \mathrm{O}$ ratio that has been measured (Nixon et al., 2008) does not seem to be required to constrain the origin of CO. It is of course important to lower the uncertainty on this ratio by future measurements to validate the present model but our model seems to indicate that it might be irrelevant for discriminating an external origin from an internal origin of $\mathrm{CO}$. The only neutral species highly dependent on the ${ }^{16} \mathrm{O} /{ }^{18} \mathrm{O}$ ratio from Enceladus is $\mathrm{H}_{2} \mathrm{CO}$. However, the abundance of $\mathrm{H}_{2} \mathrm{CO}$ in Titan's atmosphere is relatively low in our model and has never been detected from infrared observations in the lower atmosphere. It should be noted that the relative $\mathrm{H}_{2} \mathrm{CO}$ abundance in the upper atmosphere is only $1 / 10$ of the one of $\mathrm{HNC}$ which has been detected through microwave spectroscopy (Moreno et al., 2011; Cordiner et al., 2014).

\subsection{Propagation of chemical uncertainties}

The propagation of chemical uncertainties in the photochemical model of Titan has been investigated by Dobrijevic et al. (2014) and Dobrijevic et al. (2016) for neutral oxygen chemistry and the coupled ion-neutral chemistry, respectively. Associated to a global sensitivity analysis, these studies allow us to identify the key reactions that mainly contribute to the uncertainties in the model results'. In the present paper, we only present the uncertainties on the various oxygen species. The propagation of uncertainties is presented for the case of an internal source of CO.

The methodology we used to estimate the uncertainties on the photolysis rates for the different isotopologues is the following. Five species that include ${ }^{18} \mathrm{O}$ atoms are photodissociated in our model. Absorption cross sections of the 


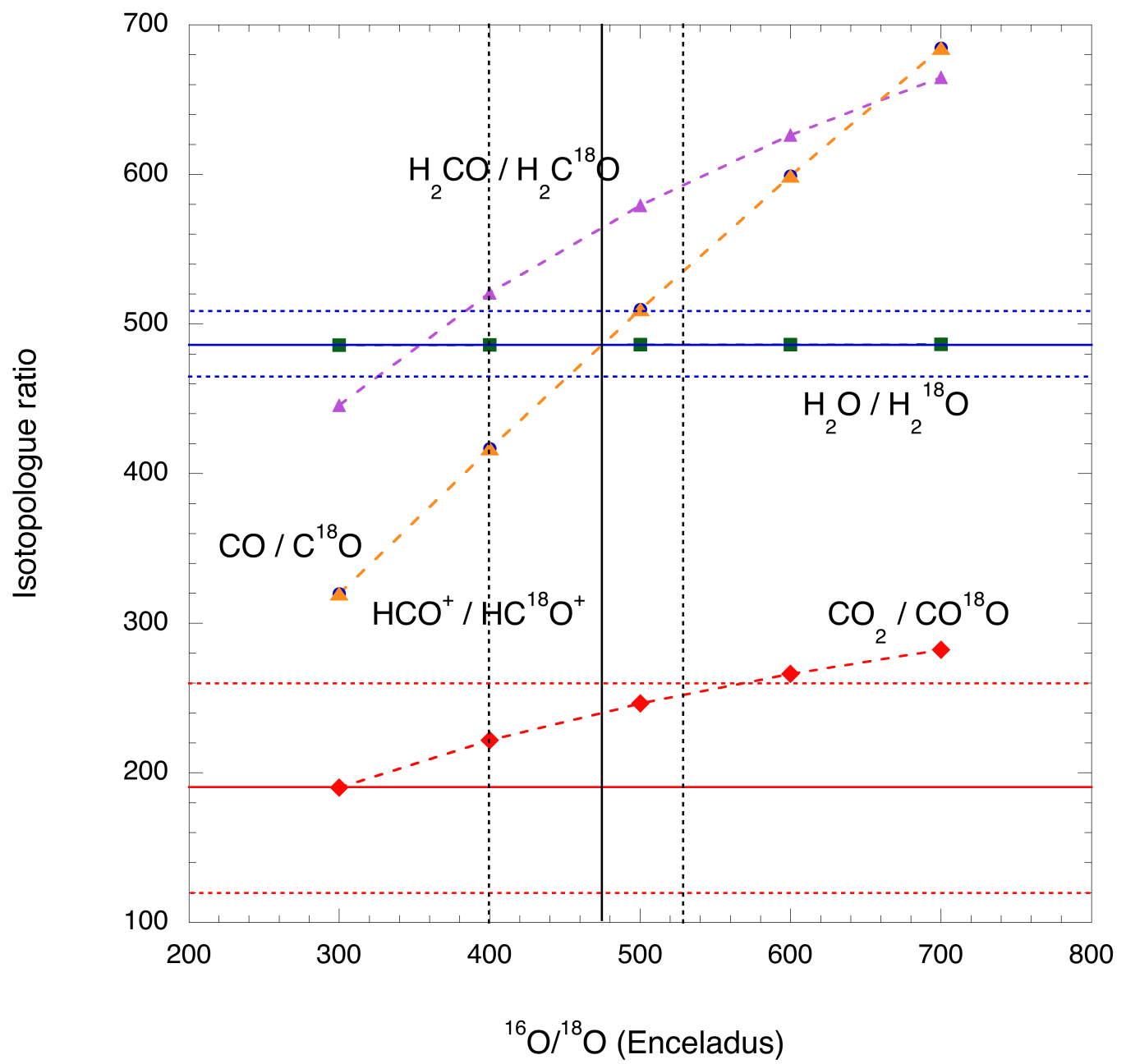

Fig. 7. The $\mathrm{CO} / \mathrm{C}^{18} \mathrm{O}$ (blue circle), $\mathrm{CO}_{2} / \mathrm{CO}^{18} \mathrm{O}$ (red diamond), $\mathrm{H}_{2} \mathrm{CO} / \mathrm{H}_{2} \mathrm{C}^{18} \mathrm{O}$ (purple triangle), $\mathrm{H}_{2} \mathrm{O} / \mathrm{H}_{2}{ }^{18} \mathrm{O}$ (green square) and $\mathrm{HCO}^{+} / \mathrm{HC}^{18} \mathrm{O}^{+}$(orange triangle) ratios at $250 \mathrm{~km}$ of altitude (region where observations are available) as a function of the ${ }^{16} \mathrm{O} /{ }^{18} \mathrm{O}$ ratio in the external flux of $\mathrm{O}\left({ }^{3} \mathrm{P}\right)$ at the higher boundary. Blue horizontal line: $\mathrm{CO} / \mathrm{C}^{18} \mathrm{O}$ value from Serigano et al. (2016) (which overlap the $\mathrm{H}_{2} \mathrm{O} / \mathrm{H}_{2}{ }^{18} \mathrm{O}$ ratios). Red horizontal line: $\mathrm{CO}_{2} / \mathrm{CO}^{18} \mathrm{O}$ value from Nixon et al. (2009). Black vertical line: ${ }^{16} \mathrm{O} /{ }^{18} \mathrm{O}$ value from Waite et al. (2009). Dashed lines represent error bars of observations.

various light oxygenated compounds studied here are relatively well known at room temperature (various studies are available). Considering uncertainties on the various measurements and also that most of the experiments have been performed at room temperature, we consider that the uncertainties on the absorption cross section values are equal to $20 \%$. This arbitrary uncertainty should be a good approximation for closed shell molecules and for HCO. We consider that the uncertainties on branching ratios are of the same order of magnitude for the oxygenated compounds studied here. Due to the Zero Point Energy (ZPE) effect (Liang et al., 2004) the absorption of heavy isotopologues (containing one ${ }^{18} \mathrm{O}$ atom) is systematically shifted to the blue due to the larger 
reduced mass. So, the difference in absorption between the light and the heavy isotopes could be considered as known. It does not depend on the uncertainties on the experimental measurements. Moreover, we can consider that the branching ratios for the photodissociation of both isomers are identical. The photodissociations of $\mathrm{CO}_{2}$ and $\mathrm{CO}^{18} \mathrm{O}$ are fairly well known (Schmidt et al., 2013), and both $\mathrm{H}_{2} \mathrm{C}^{18} \mathrm{O}$ and $\mathrm{HC}^{18} \mathrm{O}$ are photodissociated in the visible part of the spectrum. In this case, as the solar flux is relatively constant, the spectral shift induced by the ZPE effect does not lead to an important difference in the photolysis rates for the respective isotopologues. Consequently, for these systems we fixed the $J^{16} \mathrm{O} / J^{18} \mathrm{O}$ ratio (where $J^{16} \mathrm{O}$ is the photolysis rate of the light isotopologue (for instance $\mathrm{CO}$ ) and $J^{18} \mathrm{O}$ is the photolysis rate of the heavy isotopologue (for instance $\mathrm{C}^{18} \mathrm{O}$ )). The fixed value corresponds to the nominal model. So, it means that at the end of the Monte-Carlo procedure, the distribution of $J^{18} \mathrm{O}$ values has the same shape as the one of $J^{16} \mathrm{O}$ but shifted by a constant value given by the nominal $J^{16} \mathrm{O} / J^{18} \mathrm{O}$ ratio. For $\mathrm{H}_{2} \mathrm{O}$, which absorbs below $200 \mathrm{~nm}$ and should show a relatively strong ZPE effect, we used the calculated ZPE effect in the nominal model $\left(20 \mathrm{~cm}^{-1}\right)$ and we performed an additional run with a ZPE effect of $40 \mathrm{~cm}^{-1}$ leading to a very similar result. We conclude then that the uncertainty on $\mathrm{H}_{2}^{18} \mathrm{O}$ photodissociation is similar to the uncertainty on $\mathrm{H}_{2} \mathrm{O}$ photodissociation.

For the reactions involving the other isotopologues, we consider that for all the reactions the $k^{16} \mathrm{O} / k^{18} \mathrm{O}$ ratio stays constant for each Monte-Carlo run $\left(k^{16} \mathrm{O}\right.$ is the constant rate of the reaction that includes only ${ }^{16} \mathrm{O}$ atoms and $k^{18} \mathrm{O}$ is the constant rate of similar reactions including one ${ }^{18} \mathrm{O}$ atom). We considered that only a few reactions have a $k^{16} \mathrm{O} / k^{18} \mathrm{O}$ ratio different than 1 (see appendix A).

Results for the internal source of CO are summarized in Table 2. We see that due to uncertainties on the rate constants and photolysis rates, the uncertainties on some $\mathrm{XO} / \mathrm{X}^{18} \mathrm{O}$ ratios in the atmosphere are quite important. This is particularly noticeable for $\mathrm{H}_{2} \mathrm{CO} / \mathrm{H}_{2} \mathrm{C}^{18} \mathrm{O}$ in the lower atmosphere (where the abundance is low), $\mathrm{NO} / \mathrm{N}^{18} \mathrm{O}$ and $\mathrm{CH}_{2} \mathrm{OH}^{+} / \mathrm{CH}_{2}{ }^{18} \mathrm{OH}^{+}$. In the ionosphere, the uncertainty on the $\mathrm{H}_{2} \mathrm{O} / \mathrm{H}_{2}{ }^{18} \mathrm{O}$ ratio (and consequently on the $\mathrm{H}_{3} \mathrm{O}^{+} / \mathrm{H}_{3}{ }^{18} \mathrm{O}^{+}$ ratio) is also noticeable. In the ionosphere, the origin of water is a mix between diffusion from micrometeorite deposition around $750 \mathrm{~km}$, and a minor contribution from oxygen reactions (due to the $\mathrm{O}\left({ }^{3} \mathrm{P}\right.$ ) flux at the upper boundary of the model). The uncertainty on the $\mathrm{H}_{2} \mathrm{O} / \mathrm{H}_{2}{ }^{18} \mathrm{O}$ ratio is due to cycling processes involving $\mathrm{H}_{2} \mathrm{O}$ and $\mathrm{H}_{2}{ }^{18} \mathrm{O}$ photodissociations associated to reformation of $\mathrm{H}_{2} \mathrm{O}$ and $\mathrm{H}_{2}{ }^{18} \mathrm{O}$ (through the reactions of $\mathrm{OH}$ with $\mathrm{CH}_{3}$ and $\mathrm{CH}_{4}$ ) in competition with net water loss through the $\mathrm{OH}+\mathrm{CO}$ reaction (see Dobrijevic et al. (2014)). The other compounds that present high uncertainties in the lower atmosphere are $\mathrm{H}_{2} \mathrm{CO}$ and $\mathrm{NO}$ for neutrals and the four oxygen ions included in our model. Figure 8 illustrates the distributions of $\mathrm{H}_{2} \mathrm{O} / \mathrm{H}_{2}{ }^{18} \mathrm{O}$ and $\mathrm{CH}_{2} \mathrm{OH}^{+} / \mathrm{CH}_{2}{ }^{18} \mathrm{OH}^{+}$profiles generated by our Monte-Carlo procedure. 
The chemical uncertainties on the ${ }^{16} \mathrm{O} /{ }^{18} \mathrm{O}$ ratios are quite low for $\mathrm{CO}$ and $\mathrm{CO}_{2}$, the two compounds for which we have measurements. It can be noted that the uncertainties in the calculated $\mathrm{CO}_{2} / \mathrm{CO}^{18} \mathrm{O}$ ratio is much lower than the uncertainty on the observation.

Table 2

Nominal and mean ${ }^{16} \mathrm{O} /{ }^{18} \mathrm{O}$ ratios and their $1-\sigma$ uncertainty for all oxygen species in the model at two altitudes. Ratio values of $\mathrm{CO}_{2} / \mathrm{CO}^{18} \mathrm{O}$ and $\mathrm{CO} / \mathrm{C}^{18} \mathrm{O}$ inferred from observations from Nixon et al. (2009) and Serigano et al. (2016) respectively are also given for comparison.

\begin{tabular}{|c|c|c|c|c|c|}
\hline Isotopologue ratio & \multicolumn{4}{|c|}{ Model } & Observation \\
\hline & \multicolumn{2}{|c|}{ Altitude: $200 \mathrm{~km}$} & \multicolumn{2}{|c|}{ Altitude: $800 \mathrm{~km}$} & \\
\hline & Nominal & Monte-Carlo & Nominal & Monte-Carlo & \\
\hline $\mathrm{CO} / \mathrm{C}^{18} \mathrm{O}$ & 500 & $500 \pm 0$ & 505 & $505 \pm 0$ & $486 \pm 22(200-275 \mathrm{~km})$ \\
$\mathrm{H}_{2} \mathrm{O} / \mathrm{H}_{2}{ }^{18} \mathrm{O}$ & 483 & $483 \pm 11$ & 500 & $501 \pm 20$ & \\
$\mathrm{CO}_{2} / \mathrm{CO}^{18} \mathrm{O}$ & 243 & $244 \pm 3$ & 247 & $248 \pm 2$ & $190 \pm 71(100-150 \mathrm{~km})$ \\
$\mathrm{H}_{2} \mathrm{CO} / \mathrm{H}_{2} \mathrm{C}^{18} \mathrm{O}$ & 589 & $568 \pm 94$ & 484 & $485 \pm 16$ & \\
$\mathrm{HCO} / \mathrm{HC}^{18} \mathrm{O}$ & 500 & $500 \pm 0$ & 484 & $485 \pm 16$ & \\
$\mathrm{CH}_{3} \mathrm{O} / \mathrm{CH}_{3}^{18} \mathrm{O}$ & 567 & $569 \pm 8$ & 505 & $506 \pm 19$ & \\
$\mathrm{NO} / \mathrm{N}^{18} \mathrm{O}$ & 519 & $519 \pm 72$ & 536 & $544 \pm 88$ & \\
$\mathrm{OH} /{ }^{18} \mathrm{OH}$ & 497 & $497 \pm 11$ & 504 & $505 \pm 67$ & \\
$\mathrm{O}\left({ }^{3} \mathrm{P}\right) /{ }^{18} \mathrm{O}\left({ }^{3} \mathrm{P}\right)$ & 589 & $567 \pm 97$ & 507 & $507 \pm 2$ & \\
$\mathrm{O}\left({ }^{1} \mathrm{D}\right) /{ }^{18} \mathrm{O}\left({ }^{1} \mathrm{D}\right)$ & 567 & $569 \pm 8$ & 505 & $506 \pm 19$ & \\
$\mathrm{HCO}^{+} / \mathrm{HC}^{18} \mathrm{O}^{+}$ & 500 & $500 \pm 0$ & 505 & $505 \pm 0$ & \\
$\mathrm{CH}_{2} \mathrm{OH}+/ \mathrm{CH}_{2}{ }^{18} \mathrm{OH}$ & 589 & $568 \pm 94$ & 484 & $485 \pm 16$ & \\
$\mathrm{NO}^{+} / \mathrm{N}^{18} \mathrm{O}^{+}$ & 519 & $519 \pm 72$ & 536 & $544 \pm 88$ & \\
$\mathrm{H}_{3} \mathrm{O}^{+} / \mathrm{H}_{3}{ }^{18} \mathrm{O}^{+}$ & 483 & $483 \pm 11$ & 500 & $501 \pm 20$ & \\
\hline
\end{tabular}

Another way to present the results of our uncertainty propagation procedure is to present scatterplots of a species and its isotopologue. Figure 9 shows the scatterplots of $\mathrm{H}_{2} \mathrm{O}$ and $\mathrm{H}_{2} \mathrm{CO}$ mole fractions and their respective isotopologues at different altitudes. With the exception of a few points (obtained from about $10 \%$ of the runs), most of the points are gathered in a relatively narrow range of values. They also show that there is a strong correlation between the mole fraction value of a species and its isotopologue and that uncertainty on model results are about the same for the lighter isotopologue than the heavier one. As a consequence, if our procedure does not underestimate the uncertainty on the rate constants for the higher isotopologues, it would be more efficient, in order to reduce the model uncertainties, to improve the pre- 

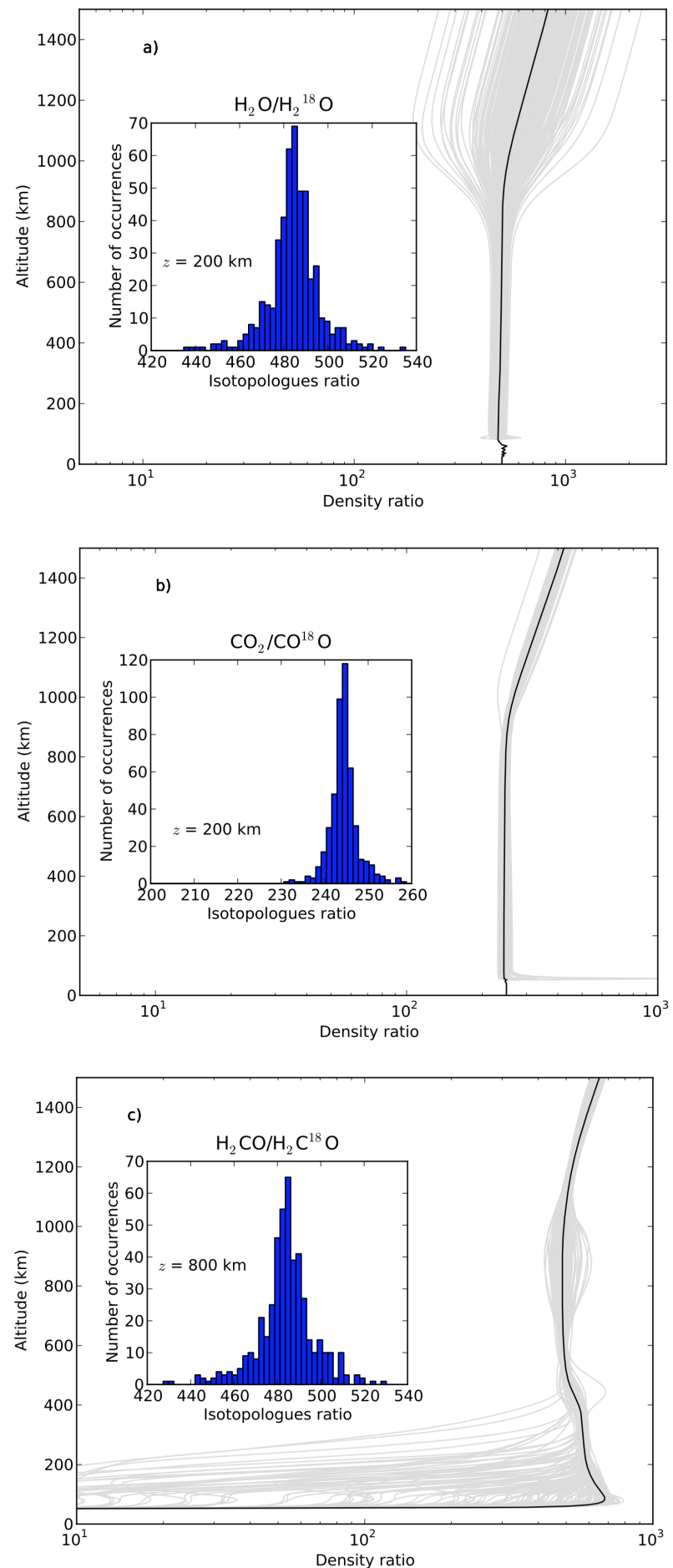

Fig. 8. Ratio profiles generated by the Monte-Carlo method and histogram at a given altitude. a) $\mathrm{H}_{2} \mathrm{O} / \mathrm{H}_{2}{ }^{18} \mathrm{O}$ at $z=200 \mathrm{~km}$. b) $\mathrm{CO}_{2} / \mathrm{CO}^{18} \mathrm{O}$ at $z=200 \mathrm{~km}$. c) $\mathrm{H}_{2} \mathrm{CO} / \mathrm{H}_{2} \mathrm{C}^{18} \mathrm{O}$ at $z=800 \mathrm{~km}$. Dark line: nominal profile. Grey lines: Monte-Carlo profiles. 
cision of the key reactions involving the lighter species; i.e. the key reactions presented in Dobrijevic et al. (2014).
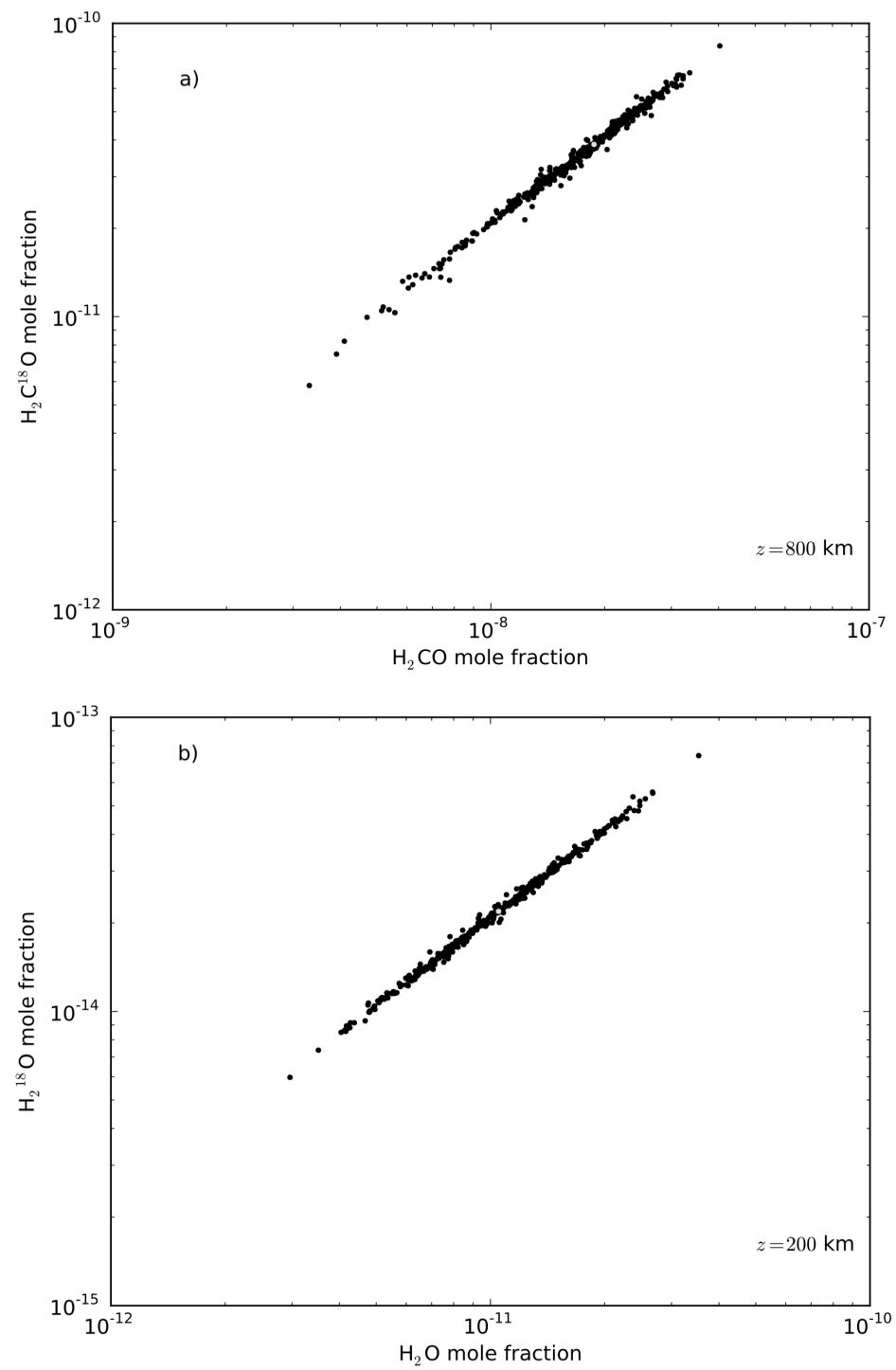

Fig. 9. a) Scatterplot of $\mathrm{H}_{2} \mathrm{CO}$ and $\mathrm{H}_{2} \mathrm{C}^{18} \mathrm{O}$ mole fractions at $800 \mathrm{~km}$. b) Scatterplot of $\mathrm{H}_{2} \mathrm{O}$ and $\mathrm{H}_{2}{ }^{18} \mathrm{O}$ mole fractions at $200 \mathrm{~km}$. Black points correspond to the 480 mole fractions generated by our uncertainty propagation procedure. Grey point correspond to our nominal results. 


\section{Discussion}

\subsection{Photochemical fractionation of ${ }^{17} \mathrm{O}$ species}

Recent ALMA observations of CO (Serigano et al., 2016) give a ${ }^{16} \mathrm{O} /{ }^{17} \mathrm{O}$ ratio equal to $2917 \pm 359$, in agreement with the terrestrial value, which is 2680.0 (Lodders, 2003). We did not perform calculations considering the photodissociation and chemistry of ${ }^{17} \mathrm{O}$ compounds, but we think that the ${ }^{16} \mathrm{O} /{ }^{17} \mathrm{O}$ ratio will follow the same trend as the ${ }^{16} \mathrm{O} /{ }^{18} \mathrm{O}$ one, the fractionation processes being of a similar amplitude. So, we do not expect a large fractionation effect for ${ }^{17} \mathrm{O}$ compounds.

\subsection{Sensitivity to micrometeorite composition}

We added several species in the micrometeorites flux (such as $\mathrm{O}_{2}, \mathrm{CO}, \mathrm{CO}_{2}$ with relative abundances corresponding to their cometary composition) to check their putative role in the chemistry. In particular, the $\mathrm{O}_{2}$ molecule has been recently detected in the coma of comet $67 \mathrm{P} /$ Churyumov-Gerasimenko (Bieler et al., 2015) with an average abundance $\mathrm{O}_{2}$ (relative to $\mathrm{H}_{2} \mathrm{O}$ ) equal to $3.80 \pm 0.85 \%$. We have investigated the effect of such abundance in micrometeorites on the ${ }^{16} \mathrm{O} /{ }^{18} \mathrm{O}$ ratio of various oxygenated compounds in Titan's atmosphere. We have built a chemical network describing the photodissociation and reactivity of $\mathrm{O}_{2}$ and $\mathrm{O}^{18} \mathrm{O}$ (chemical scheme presented in appendix A). However, despite the different photodissociation efficiencies of $\mathrm{O}_{2}$ and $\mathrm{O}^{18} \mathrm{O}$ (Yoshino et al., 1989), the $\mathrm{O}_{2} / \mathrm{O}^{18} \mathrm{O}$ input does not have any effect on oxygen compounds fractionation. This is due to the fact that $\mathrm{O}_{2} / \mathrm{O}^{18} \mathrm{O}$ is quickly consumed in Titan's atmosphere (through photodissociation and reaction with $\mathrm{CH}_{3}$ ) and are transformed into $\mathrm{CO} / \mathrm{C}^{18} \mathrm{O}$ (and a small fraction into $\mathrm{H}_{2} \mathrm{O} / \mathrm{HO}^{18} \mathrm{O}$ ). As there is no efficient $\mathrm{O}_{2}$ production, there is no $\mathrm{O}_{2}$ recycling and then no possibility of oxygen fractionation. Potential $\mathrm{O}_{2}$ input from micrometeorites leads only to a small increase of the abundances of oxygen compounds. So, we do not consider $\mathrm{O}_{2}$ and $\mathrm{O}^{18} \mathrm{O}$ in our nominal model. Similarly, the addition of cometary $\mathrm{CO}$ and $\mathrm{CO}_{2}$ in micrometeorites has no significant effect on the abundance of the main oxygen species, nor on their isotopic ratio.

We have also investigated the role of the uncertainty on the $\mathrm{H}_{2} \mathrm{O} / \mathrm{H}_{2}^{18} \mathrm{O}$ ratio coming from micrometeorites. Regarding the values published in the literature (see section 2.3), the ${ }^{16} \mathrm{O} /{ }^{18} \mathrm{O}$ ratio in micrometeorites ranges from 370 to 626 (in $\mathrm{H}_{2} \mathrm{O}$ ). In Figure 10 we show the results we obtained varying this ratio in the influx of $\mathrm{H}_{2} \mathrm{O}$ and keeping the external ${ }^{16} \mathrm{O} /{ }^{18} \mathrm{O}$ ratio constant and equal to 
500. $\mathrm{CO}$ and $\mathrm{CO}_{2}$ show little variations as a function of ${ }^{16} \mathrm{O} /{ }^{18} \mathrm{O}$ ratio in $\mathrm{H}_{2} \mathrm{O}$. However, measurements are not compatible with a $\mathrm{H}_{2} \mathrm{O} / \mathrm{H}_{2}^{18} \mathrm{O}$ ratio greater than 600 . A more precise determination of the $\mathrm{CO}_{2} / \mathrm{CO}^{18} \mathrm{O}$ ratio would give a valuable constraint on the $\mathrm{H}_{2} \mathrm{O} / \mathrm{H}_{2}^{18} \mathrm{O}$ ratio in micrometeorites. As mentioned before, the $\mathrm{H}_{2} \mathrm{CO} / \mathrm{H}_{2} \mathrm{C}^{18} \mathrm{O}$ ratio shows strong variations with the $\mathrm{H}_{2} \mathrm{O} / \mathrm{H}_{2}^{18} \mathrm{O}$ ratio. We obtain the same results when considering an internal source of CO.

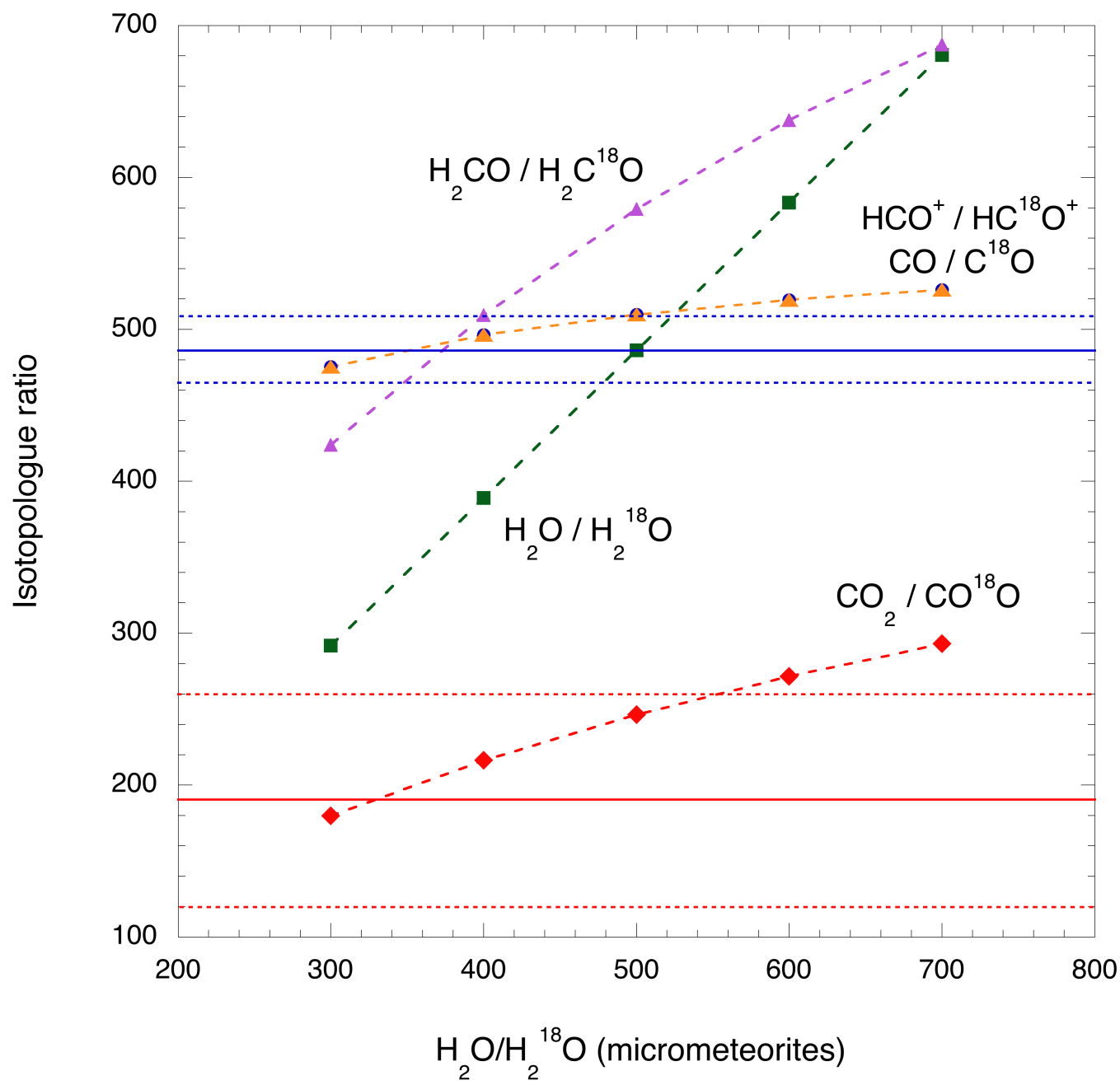

Fig. 10. The $\mathrm{CO} / \mathrm{C}^{18} \mathrm{O}$ (blue circle), $\mathrm{CO}_{2} / \mathrm{CO}^{18} \mathrm{O}$ (red diamond), $\mathrm{H}_{2} \mathrm{CO} / \mathrm{H}_{2} \mathrm{C}^{18} \mathrm{O}$ (purple triangle), $\mathrm{H}_{2} \mathrm{O} / \mathrm{H}_{2}{ }^{18} \mathrm{O}$ (green square) and $\mathrm{HCO}^{+} / \mathrm{HC}^{18} \mathrm{O}^{+}$(orange triangle) ratios at $250 \mathrm{~km}$ of altitude (region where observations are available) as a function of the $\mathrm{H}_{2} \mathrm{O} / \mathrm{HO}^{18} \mathrm{O}$ ratio in the micrometeorite flux of $\mathrm{H}_{2} \mathrm{O}$ around $750 \mathrm{~km}$. Blue horizontal line: $\mathrm{CO} / \mathrm{C}^{18} \mathrm{O}$ value from Serigano et al. (2016). Red horizontal line: $\mathrm{CO}_{2} / \mathrm{CO}^{18} \mathrm{O}$ value from Nixon et al. (2009). 


\subsection{Sensitivity to $\mathrm{H}_{2}{ }^{18} \mathrm{O}$ absorption cross section}

To our knowledge, the photodissociation cross section of $\mathrm{H}_{2}^{18} \mathrm{O}$ has not been measured, in contrast to $\mathrm{C}^{18} \mathrm{O}$ and $\mathrm{CO}^{18} \mathrm{O}$. We estimate it from the $\mathrm{H}_{2} \mathrm{O}$ photodissociation cross section using the ZPE effect (Liang et al., 2004) which is a rough approximation. The $\mathrm{ZPE}$ effect shifts the absorption of $\mathrm{H}_{2}^{18} \mathrm{O}$ to the blue, a shift equal to the difference of the $\mathrm{ZPE}$ of the ground vibrational states of $\mathrm{H}_{2} \mathrm{O}$ and $\mathrm{H}_{2}^{18} \mathrm{O}$ calculated to be equal to $20 \mathrm{~cm}^{-1}$. As the ZPE effect is a rough approximation we varied the shift of the $\mathrm{H}_{2}^{18} \mathrm{O}$ absorption to see if the value of the shift is critical. Using a shift of $40 \mathrm{~cm}^{-1}$ leads to very similar results. The photodissociation is the main loss, along with condensation, of water in Titan's atmosphere, and the difference between $\mathrm{H}_{2} \mathrm{O}$ and $\mathrm{H}_{2}^{18} \mathrm{O}$ photodissociation seems too small to induce a strong enrichment. However, uncertainty on the $\mathrm{H}_{2}^{18} \mathrm{O}$ photodissociation may be underestimated using $\mathrm{ZPE}$ effect and experimental measurements will be of great help to improve this point.

\subsection{Comparison with previous photochemical models}

Wong et al. (2002) developed a photochemical model to explain the preliminary value of ${ }^{16} \mathrm{O} /{ }^{18} \mathrm{O}$ in $\mathrm{CO}$ obtained by Owen et al. (1999), which was about half of the cometary value. Due to the low dilution of $\mathrm{C}^{18} \mathrm{O}$ with time inferred from their model, they inferred that a strong initial $\mathrm{C}^{18} \mathrm{O}$ enrichment of 3.23 is required to be compatible with these observations. In fact, due to the recent observations of oxygen species (especially $\mathrm{H}_{2} \mathrm{O}$ ) and the new determination of isotopic ratios in $\mathrm{CO}$ and $\mathrm{CO}_{2}$ (which are compatible with a cometary ${ }^{16} \mathrm{O} /{ }^{18} \mathrm{O}$ ratio), the model of Wong et al. (2002) would rather suggest that there was a low or no $\mathrm{C}^{18} \mathrm{O}$ enrichment at all $4.6 \mathrm{Gyr}$ ago.

Recently, Lara et al. (2014) proposed that a time-variable Enceladus source could explain the discrepancy of the relative $\mathrm{H}_{2} \mathrm{O}$ and $\mathrm{CO}_{2}$ profiles between the photochemical models and observations. According to the present work, the isotopic ratio in $\mathrm{CO}$ and $\mathrm{CO}_{2}$ requires a cometary ${ }^{16} \mathrm{O} /{ }^{18} \mathrm{O}$ ratio influx (in $\mathrm{O}\left({ }^{3} \mathrm{P}\right)$ from Enceladus' plumes or in $\mathrm{CO}$ from the surface, and in $\mathrm{H}_{2} \mathrm{O}$ from micrometeorites). Unfortunately, the measurement of the oxygen isotopic ratio in Enceladus' plumes (Waite et al., 2009) does not give an additional constraint to test this hypothesis. 


\section{Conclusion}

We have developed a photochemical model of oxygen isotopologues to bring some new theoretical constraints on the origin of oxygen species in Titan's atmosphere. Our model gives satisfactory results concerning the main oxygen species and their isotopologues. In particular, the current isotopic fractionation observed in $\mathrm{CO}$ and $\mathrm{CO}_{2}$ can either be explained by an internal source of $\mathrm{CO}$ or by an external source of oxygen atoms from Enceladus' plumes, both with a micrometeoritic influx of water, assuming that all these sources have a cometary ${ }^{16} \mathrm{O} /{ }^{18} \mathrm{O}$ ratio.

If the origin of $\mathrm{CO}$ is external (reaching its present concentration after $3.17 \times$ $10^{8}$ years of accumulation), $\mathrm{CO}$ is produced from a set of reactions that begins with the reaction $\mathrm{O}\left({ }^{3} \mathrm{P}\right)+\mathrm{CH}_{3}$, the contribution from $\mathrm{OH}+\mathrm{CH}_{3}$ being almost negligible $\left(1 / 50\right.$ of the $\left.\mathrm{O}\left({ }^{3} \mathrm{P}\right)+\mathrm{CH}_{3}\right)$. Our results suggest that the ${ }^{16} \mathrm{O} /{ }^{18} \mathrm{O}$ ratio in $\mathrm{CO}$ is then mainly controlled by the ${ }^{16} \mathrm{O} /{ }^{18} \mathrm{O}$ ratio in $\mathrm{O}\left({ }^{3} \mathrm{P}\right)$. Measurements of the oxygen isotopic ratio in Enceladus' plumes is in agreement with this statement. In order to give more reliable conclusions on the origin of oxygen, it would be very helpful to determine the origin of the discrepancies between the various measurements of $\mathrm{H}_{2} \mathrm{O}$ abundances in the stratosphere (CIRS and Herschel observations) and to lower the uncertainty on the measured $\mathrm{CO}_{2} / \mathrm{CO}^{18} \mathrm{O}$ ratio. New measurements, even at low spatial resolution, are necessary to move this work forward. In particular, according to Dobrijevic et al. (2014) and the present work, the detection of new oxygen species in Titan's atmosphere would provide valuable constraints for photochemical models.

Clearly, our study shows that oxygen fractionation is low in Titan's atmosphere. In the higher atmosphere, above the homopause, oxygen fractionation is controlled by molecular diffusion. Photochemical fractionation, the most efficient fractionation process in Titan's atmosphere apart from molecular diffusion, is only efficient in the lower stratosphere. The main species subject to this fractionation, taking chemical uncertainties into account, are $\mathrm{H}_{2} \mathrm{CO}$, $\mathrm{H}_{2} \mathrm{O}$, NO and some oxygen ions like $\mathrm{CH}_{2} \mathrm{OH}^{+}$. The most efficient reaction is the $\mathrm{OH}+\mathrm{CO}$ reaction. The $\mathrm{CO}+\mathrm{HCO}^{+}$reaction involves high flux but as $\mathrm{HCO}^{+}$is involved in reactions leading ultimately back to $\mathrm{CO}$, this reaction does not lead to any isotopic $\mathrm{C}^{18} \mathrm{O}$ fractionation, but instead controls the $\mathrm{HCO}^{+} / \mathrm{HC}^{18} \mathrm{O}^{+}$ratio.

Differences in photolysis between ${ }^{16} \mathrm{O}$ and ${ }^{18} \mathrm{O}$ compounds are small in our model. However, in some cases, such as $\mathrm{H}_{2} \mathrm{O}$ photolysis, the effect may not be negligible. So, precise photodissociation cross sections of $\mathrm{H}_{2}^{18} \mathrm{O}$ are needed to lower the uncertainties in the modeled $\mathrm{H}_{2} \mathrm{O} / \mathrm{H}_{2}^{18} \mathrm{O}$ fractionation. 


\section{A List of reactions}

B Cross sections and branching ratios of the oxygen species and their isotopologues considered in the present paper

\section{$\mathrm{C}$ Integrated production and loss rates for the nominal internal model of $\mathrm{CO}$}

\section{Acknowledgements}

We thank the Programme National de Plantologie (PNP) of the Institut National des Sciences de lUnivers (INSU) for funding this work. This work is also supported by the Dutch astrochemistry network (DAN) from the Netherlands Organisation for Scientific Research (NWO) under grant 648.000.002. We are grateful to the anonymous referees for the constructive comments about this manuscript.

\section{References}

B. Bézard, R. V. Yelle, and C. A. Nixon. Chapter 6 - The composition of Titan's atmosphere. In Titan: Interior, Surface, Atmosphere, and Space Environment. Cambridge Univ. Press., 2012.

A. Bieler, K. Altwegg, H. Balsiger, A. Bar-Nun, J.-J. Berthelier, P. Bochsler, C. Briois, U. Calmonte, M. Combi, J. de Keyser, E. F. van Dishoeck, B. Fiethe, S. A. Fuselier, S. Gasc, T. I. Gombosi, K. C. Hansen, M. Hässig, A. Jäckel, E. Kopp, A. Korth, L. Le Roy, U. Mall, R. Maggiolo, B. Marty, O. Mousis, T. Owen, H. Rème, M. Rubin, T. Sémon, C.-Y. Tzou, J. H. Waite, C. Walsh, and P. Wurz. Abundant molecular oxygen in the coma of comet 67P/Churyumov-Gerasimenko. Nature, 526:678-681, October 2015. doi: 10.1038/nature15707.

N. Biver, D. Bockelée-Morvan, J. Crovisier, A. Lecacheux, U. Frisk, A. Hjalmarson, M. Olberg, H.-G. Florén, A. Sandqvist, and S. Kwok. Submillimetre observations of comets with Odin: 2001 2005. Planetary and Space Sciences, 55:1058-1068, June 2007. doi: 10.1016/j.pss.2006.11.010.

D. Bockelée-Morvan, N. Biver, B. Swinyard, M. de Val-Borro, J. Crovisier, P. Hartogh, D. C. Lis, R. Moreno, S. Szutowicz, E. Lellouch, M. Emprechtinger, G. A. Blake, R. Courtin, C. Jarchow, M. Kidger, M. Küppers, M. Rengel, G. R. Davis, T. Fulton, D. Naylor, S. Sidher, and H. Walker. Herschel measurements of the $\mathrm{D} / \mathrm{H}$ and ${ }^{16} \mathrm{O} /{ }^{18} \mathrm{O}$ ratios in water in the Oort- 
cloud comet C/2009 P1 (Garradd). Astronomy and Astrophysics, 544:L15, August 2012. doi: 10.1051/0004-6361/201219744.

T. A. Cassidy and R. E. Johnson. Collisional spreading of Enceladus' neutral cloud. Icarus, 209:696-703, October 2010. doi: 10.1016/j.icarus.2010.04.010.

Wei-Chen Chen and R. A. Marcus. On the theory of the co + oh reaction, including $\mathrm{h}$ and $\mathrm{c}$ kinetic isotope effects. The Journal of Chemical Physics, 123(9):094307-16, 2005. URL http://dx.doi.org/10.1063/1.2031208.

I.D. Clark and P. Fritz. Environmental Isotopes in Hydrogeology. Taylor and Francis, 1997. ISBN 9781566702492. URL https://books.google.fr/books?id=0N2XmjqXFRAC.

M. A. Cordiner, C. A. Nixon, N. A. Teanby, P. G. J. Irwin, J. Serigano, S. B. Charnley, S. N. Milam, M. J. Mumma, D. C. Lis, G. Villanueva, L. Paganini, Y.-J. Kuan, and A. J. Remijan. ALMA Measurements of the HNC and $\mathrm{HC}_{3} \mathrm{~N}$ Distributions in Titan's Atmosphere. The Astrophysical Journal Letters, 795:L30, November 2014. doi: 10.1088/2041-8205/795/2/L30.

V. Cottini, C. A. Nixon, D. E. Jennings, C. M. Anderson, N. Gorius, G. L. Bjoraker, A. Coustenis, N. A. Teanby, R. K. Achterberg, B. Bézard, R. de Kok, E. Lellouch, P. G. J. Irwin, F. M. Flasar, and G. Bampasidis. Water vapor in Titan's stratosphere from Cassini CIRS far-infrared spectra. Icarus, 220:855-862, August 2012. doi: 10.1016/j.icarus.2012.06.014.

R. Courtin, B. M. Swinyard, R. Moreno, T. Fulton, E. Lellouch, M. Rengel, and P. Hartogh. First results of Herschel-SPIRE observations of Titan. Astronomy and Astrophysics, 536:L2, December 2011. doi: 10.1051/0004$6361 / 201118304$.

R. de Kok, P. G. J. Irwin, N. A. Teanby, E. Lellouch, B. Bézard, S. Vinatier, C. A. Nixon, L. Fletcher, C. Howett, S. B. Calcutt, N. E. Bowles, F. M. Flasar, and F. W. Taylor. Oxygen compounds in Titan's stratosphere as observed by Cassini CIRS. Icarus, 186:354-363, February 2007. doi: 10.1016/j.icarus.2006.09.016.

M. Dobrijevic, E. Hébrard, J. C. Loison, and K. M. Hickson. Coupling of oxygen, nitrogen, and hydrocarbon species in the photochemistry of Titan's atmosphere. Icarus, 228:324-346, January 2014. doi: 10.1016/j.icarus.2013.10.015.

M. Dobrijevic, J. C. Loison, K. M. Hickson, and G. Gronoff. 1D-coupled photochemical model of neutrals, cations and anions in the atmosphere of Titan. Icarus, 268:313-339, April 2016. doi: 10.1016/j.icarus.2015.12.045.

P. Eberhardt, M. Reber, D. Krankowsky, and R. R. Hodges. The D/H and ${ }^{18} \mathrm{O} /{ }^{16} \mathrm{O}$ ratios in water from comet $\mathrm{P} /$ Halley. Astronomy and Astrophysics, 302:301, October 1995.

Karen L. Feilberg, Matthew S. Johnson, and Claus J. Nielsen. Relative rates of reaction of $13 \mathrm{c} 16 \mathrm{o}, 12 \mathrm{c} 18 \mathrm{o}, 12 \mathrm{c} 17 \mathrm{o}$ and $13 \mathrm{c} 18 \mathrm{o}$ with oh and od radicals. Physical Chemistry Chemical Physics, 7(11):2318-2323, 2005. ISSN 14639076. URL http://dx.doi.org/10.1039/B503350K.

M. Gurwell, R. Moreno, A. Moullet, and B. Butler. Titan's Stratosphere: Isotopic Ratios in CO and HCN. In EPSC-DPS Joint Meeting 2011, page 
270, October 2011.

M. A. Gurwell. Carbon, Nitrogen And Oxygen Isotopic Ratios In Titan's Stratosphere. In AAS/Division for Planetary Sciences Meeting Abstracts \#40, volume 40 of Bulletin of the American Astronomical Society, page 423, September 2008.

M. Hamberg, W. D. Geppert, R. D. Thomas, V. Zhaunerchyk, F. sterdahl, A. Ehlerding, M. Kaminska, J. Semaniak, M. af Ugglas, A. Kllberg, A. Paal, A. Simonsson, and M. Larsson. Experimental determination of dissociative recombination reaction pathways and absolute reaction cross-sections of ch2oh ${ }^{+}$, cd2od $^{+}$and cd2. Molecular Physics, 105(5-7):899-906, 2007. doi: 10.1080/00268970701206642.

R. E. Hartle, E. C. Sittler, F. M. Neubauer, R. E. Johnson, H. T. Smith, F. Crary, D. J. McComas, D. T. Young, A. J. Coates, D. Simpson, S. Bolton, D. Reisenfeld, K. Szego, J. J. Berthelier, A. Rymer, J. Vilppola, J. T. Steinberg, and N. Andre. Initial interpretation of Titan plasma interaction as observed by the Cassini plasma spectrometer: Comparisons with Voyager 1. Planetary and Space Science, 54:1211-1224, October 2006. doi: 10.1016/j.pss.2006.05.029.

R. Hesse and W. E. Harrison. Gas hydrates (clathrates) causing pore-water freshening and oxygen isotope fractionation in deep-water sedimentary sections of terrigenous continental margins. Earth and Planetary Science Letters, 55:453-462, November 1981. doi: 10.1016/0012-821X(81)90172-2.

S. M. Hörst, V. Vuitton, and R. V. Yelle. Origin of oxygen species in Titan's atmosphere. Journal of Geophysical Research (Planets), 113:E10006, October 2008. doi: 10.1029/2008JE003135.

D. Hutsemékers, J. Manfroid, E. Jehin, J.-M. Zucconi, and C. Arpigny. The ${ }^{16} \mathrm{OH} /{ }^{18} \mathrm{OH}$ and $\mathrm{OD} / \mathrm{OH}$ isotope ratios in comet $\mathrm{C} / 2002 \mathrm{~T} 7$ (LINEAR). Astronomy and Astrophysics, 490:L31-L34, November 2008. doi: 10.1051/0004-6361:200810833.

Edward C. Y. Inn. Rate of recombination of oxygen atoms and co at temperatures below ambient. The Journal of Chemical Physics, 61 (4):1589-1590, 1974. doi: doi:http://dx.doi.org/10.1063/1.1682139. URL http://scitation.aip.org/content/aip/journal/jcp/61/4/10.1063/1.1682139.

Sigmund Jaffe and Fritz S. Klein. Isotopic exchange reactions of atomic oxygen produced by the photolysis of no2 at 3660 a. Transactions of the Faraday Society, 62(0):3135-3141, 1966. ISSN 0014-7672. URL http://dx.doi.org/10.1039/TF9666203135.

V. A. Krasnopolsky. A photochemical model of Titan's atmosphere and ionosphere. Icarus, 201:226-256, May 2009. doi: 10.1016/j.icarus.2008.12.038.

L. M. Lara, E. Lellouch, M. González, R. Moreno, and M. Rengel. A timedependent photochemical model for Titan's atmosphere and the origin of $\mathrm{H}_{2} \mathrm{O}$. Astronomy and Astrophysics, 566:A143, June 2014. doi: 10.1051/0004$6361 / 201323085$.

Mao-Chang Liang, Geoffrey A. Blake, and Yuk L. Yung. A semianalytic model for photo-induced isotopic fractionation in simple 
molecules. Journal of Geophysical Research: Atmospheres, 109(D10): n/a-n/a, 2004. ISSN 2156-2202. doi: 10.1029/2004jd004539. URL http://dx.doi.org/10.1029/2004JD004539.

K. Lodders. Solar System Abundances and Condensation Temperatures of the Elements. The Astrophysical Journal, 591:1220-1247, July 2003. doi: $10.1086 / 375492$.

J. C. Loison, E. Hébrard, M. Dobrijevic, K. M. Hickson, F. Caralp, V. Hue, G. Gronoff, O. Venot, and Y. Bénilan. The neutral photochemistry of nitriles, amines and imines in the atmosphere of Titan. Icarus, 247:218-247, February 2015. doi: 10.1016/j.icarus.2014.09.039.

Sasadhar Mahata and S. K. Bhattacharya. Anomalous enrichment of [sup 17]o and [sup 13]c in photodissociation products of co[sub 2]: Possible role of nuclear spin. The Journal of Chemical Physics, 130(23):234312-17, 2009. URL http://dx.doi.org/10.1063/1.3153845.

R. Moreno, E. Lellouch, L. M. Lara, R. Courtin, D. Bockelée-Morvan, P. Hartogh, M. Rengel, N. Biver, M. Banaszkiewicz, and A. González. First detection of hydrogen isocyanide (HNC) in Titan's atmosphere. Astronomy and Astrophysics, 536:L12, December 2011. doi: 10.1051/0004-6361/201118189.

R. Moreno, E. Lellouch, L. M. Lara, H. Feuchtgruber, M. Rengel, P. Hartogh, and R. Courtin. The abundance, vertical distribution and origin of $\mathrm{H}_{2} \mathrm{O}$ in Titan's atmosphere: Herschel observations and photochemical modelling. Icarus, 221:753-767, November 2012. doi: 10.1016/j.icarus.2012.09.006.

H. B. Niemann, S. K. Atreya, J. E. Demick, D. Gautier, J. A. Haberman, D. N. Harpold, W. T. Kasprzak, J. I. Lunine, T. C. Owen, and F. Raulin. Composition of Titan's lower atmosphere and simple surface volatiles as measured by the Cassini-Huygens probe gas chromatograph mass spectrometer experiment. Journal of Geophysical Research (Planets), 115:E12006, December 2010. doi: 10.1029/2010JE003659.

C. A. Nixon, D. E. Jennings, B. Bézard, N. A. Teanby, R. K. Achterberg, A. Coustenis, S. Vinatier, P. G. J. Irwin, P. N. Romani, T. Hewagama, and F. M. Flasar. Isotopic Ratios in Titan's Atmosphere from Cassini CIRS Limb Sounding: $\mathrm{CO}_{2}$ at Low and Midlatitudes. The Astrophysical Journal, 681:L101-L103, July 2008. doi: 10.1086/590553.

C. A. Nixon, N. A. Teanby, S. B. Calcutt, S. Aslam, D. E. Jennings, V. G. Kunde, F. M. Flasar, P. G. Irwin, F. W. Taylor, D. A. Glenar, and M. D. Smith. Infrared limb sounding of Titan with the Cassini Composite InfraRed Spectrometer: effects of the mid-IR detector spatial responses. Applied Optics, 48:1912, March 2009. doi: 10.1364/AO.48.001912.

T. Owen, N. Biver, A. Marten, H. Matthews, and R. Meier. Saturn VI (Titan). IAU circ., 7306:3, November 1999.

J. C. Rienstra-Kiracofe, G. S. Tschumper, H. F. Schaefer, S. Nandi, and G. B. Ellison. Atomic and Molecular Electron Affinities: Photoelectron Experiments and Theoretical Computations. Chemical Reviews, 102(1):231-282, 2002. doi: $10.1021 /$ cr990044u.

T. Rockmann, C. A. M. Brenninkmeijer, G. Saueressig, P. Bergamaschi, J. N. 
Crowley, H. Fischer, and P. J. Crutzen. Mass-independent oxygen isotope fractionation in atmospheric co as a result of the reaction co + oh. Science, 281(5376):544-546, 1998. doi: 10.1126/science.281.5376.544. URL http://www . sciencemag. org/content/281/5376/544. abstract.

Johan A. Schmidt, Matthew S. Johnson, and Reinhard Schinke. Carbon dioxide photolysis from 150 to $210 \mathrm{~nm}$ : Singlet and triplet channel dynamics, uv-spectrum, and isotope effects. PNAS, 110 (44):17691-17696, 2013. doi: 10.1073/pnas.1213083110. URL http: //www . pnas . org/content/110/44/17691. abstract.

J. Serigano, C. A. Nixon, M. A. Cordiner, P. G. J. Irwin, N. A. Teanby, S. B. Charnley, and J. E. Lindberg. Isotopic Ratios of Carbon and Oxygen in Titan's CO using ALMA. The Astrophysical Journal Letters, 821:L8, April 2016. doi: 10.3847/2041-8205/821/1/L8.

R. Simonaitis and Julian Heicklen. Kinetics and mechanism of the reaction of o $([\sup 3] \mathrm{p})$ with carbon monoxide. The Journal of Chemical Physics, 56 (5):2004-2011, 1972. URL http://dx.doi.org/10.1063/1.1677490.

E. C. Sittler, A. Ali, J. F. Cooper, R. E. Hartle, R. E. Johnson, A. J. Coates, and D. T. Young. Heavy ion formation in Titan's ionosphere: Magnetospheric introduction of free oxygen and a source of Titan's aerosols? Planetary and Space Science, 57:1547-1557, November 2009. doi: 10.1016/j.pss.2009.07.017.

C. M. Stevens, Louis Kaplan, Robert Gorse, Susan Durkee, Michael Compton, Sidney Cohen, and Karen Bielling. The kinetic isotope effect for carbon and oxygen in the reaction co + oh. International Journal of Chemical Kinetics, 12(12):935-948, 1980. ISSN 1097-4601. doi: 10.1002/kin.550121205. URL http://dx.doi.org/10.1002/kin.550121205.

N. A. Teanby, P. G. J. Irwin, R. de Kok, and C. A. Nixon. Mapping Titan's HCN in the far infra-red: implications for photochemistry. Faraday Discussions, 147:51, 2010. doi: 10.1039/c001690j.

W. Alexander Van Hook. Vapor pressures of the isotopic waters and ices. The Journal of Physical Chemistry, 72(4):1234-1244, 1968. ISSN 0022-3654. doi: 10.1021/j100850a028. URL http://dx.doi.org/10.1021/j100850a028.

J. H. Waite, Jr., W. S. Lewis, B. A. Magee, J. I. Lunine, W. B. McKinnon, C. R. Glein, O. Mousis, D. T. Young, T. Brockwell, J. Westlake, M.-J. Nguyen, B. D. Teolis, H. B. Niemann, R. L. McNutt, M. Perry, and W.-H. Ip. Liquid water on Enceladus from observations of ammonia and ${ }^{40} \mathrm{Ar}$ in the plume. Nature, 460:487-490, July 2009. doi: 10.1038/nature08153.

A.-S. Wong, C. G. Morgan, Y. L. Yung, and T. Owen. Evolution of CO on Titan. Icarus, 155:382-392, February 2002. doi: 10.1006/icar.2001.6720.

K. Yoshino, D. E. Freeman, J. R. Esmond, R. S. Friedman, and W. H. Parkinson. High resolution absorption cross-sections and band oscillator strengths of the schumann-runge absorption bands of isotopic oxygen, 16o 18o, at 79 k. Planetary and Space Science, 37(4):419-426, 1989. ISSN 0032-0633. doi: http://dx.doi.org/10.1016/0032-0633(89)90123-2. URL http://www.sciencedirect.com/science/article/pii/0032063389901232. 